\title{
Extraordinary morphological changes in valve morphology during the ontogeny of several species of the Australian ostracod genus Bennelongia (Crustacea, Ostracoda)
}

\author{
Patrick DE DECKKER ${ }^{1,3,{ }^{*}}$ \& Koen MARTENS ${ }^{2,4,5}$ \\ ${ }^{3}$ Research School of Earth Sciences, The Australian National University, \\ Canberra ACT 0200, Australia. \\ ${ }^{4}$ Royal Belgian Institute of Natural Sciences, Vautierstraat 29, B-1000 Brussels, Belgium. \\ ${ }^{5}$ University of Ghent, Department of Biology, K. L. Ledeganckstraat 35, B-9000 Gent, Belgium. \\ * corresponding author e-mail: patrick.dedeckker@anu.edu.au \\ ${ }^{1}$ urn:lsid:zoobank.org:author:9B28B6EE-BC86-4CD6-A9E8-2BE36ED6FC57 \\ ${ }^{2}$ urn:Isid:zoobank.org:author:9272757B-A9E5-4C94-B28D-F5EFF32AADC7
}

\begin{abstract}
Ostracods belonging to the genus Bennelongia differ much in valve morphology between adults and juveniles. Adult valves are asymmetrical, characterised by a beak-like feature in the anteroventral region of the left valve, and, with some notable exceptions, mostly have smooth or weaklyornamented valves. Juvenile specimens, on the other hand, have valves that are almost symmetrical, with no beak-like feature and are often heavily ornamented.
\end{abstract}

We have examined the last 3 - 4 juvenile stages of 6 Bennelongia species from 5 different lineages, in order to decipher the types of external valve ornamentation and their recurrences during ontogeny and across lineages. It is clear that ornamentation is more prevalent at the early instar stages compared to the last 2 pre-adult stages, and especially when compared to the adult stage itself.

We also examined the surprising presence of a calcified inner lamella with a prominent inner list in the pre-adult stages of Bennelongia species, that is usually absent in juveniles of other ostracods, thus questioning if heterochronic processes have provided an intermediate valve morphology between the simple (normal) cypridinid juvenile state and the heavily derived and modified state of adult Bennelongia.

We discuss the possible (speculative) functionality of the ornamentation in juveniles.

Key words. Moulting, instar, nodes, pore morphology, setae.

De Deckker P. \& Martens K. 2013. Extraordinary morphological changes in valve morphology during the ontogeny of several species of the Australian ostracod genus Bennelongia (Crustacea, Ostracoda). European Journal of Taxonomy 36: 1-37. http://dx.doi.org/10.5852/ejt.2013.36 


\section{Introduction}

\section{Ostracod growth and moulting}

Ostracods, being arthropods, moult a certain number of times before reaching maturity. This applies to both their calcified valves, as well as to their soft parts. It is now well-documented (Kesling 1951; Benson \& McDonald 1963; De Deckker et al. 1979; Smith \& Martens 2000) that juvenile ostracod valves are shed before new, larger ones are calcified. This process stops when adulthood is reached, a process called 'determinate growth', in contrast with other crustaceans (e.g., prawns, lobsters) (Martens 1985). Immediately after valve calcification starts, the valves appear well-formed, but they are not completely calcified. Moulting and subsequent calcification must be a fairly rapid process, because the organism is prone to predation the first hours and even days after moulting, as its protective bi-valved carapace is temporarily missing while new valves are being calcified. The rate of calcification is controlled by the water chemistry and the ambient water temperature, with several experiments showing that calcification of some species is slower at lower temperatures (Chivas et al. 1983).

Different moults are easily recognised in ostracod valves, as growth is by increments; a rapid measurement of valve length versus height for any species clearly shows discrete length/height plots for different moult stages (Benson \& McDonald 1963; De Deckker et al. 1979).

Sexual dimorphism is also noticeable in the valves of many ostracod species, but it is mostly only apparent at the (last) adult stage: a difference in size may occur, but also in the posterior carapace morphology. This part of the carapace may be laterally expanded, for example, in order to accommodate a large number of eggs in the brood pouches of females (for example in most Darwinulidae and Timiriaseviinae, e.g., Gomphocythere etc.) or, conversely, may be enlarged along the anterior-posterior axis, to allow for the two large hemipenes in males that may, at times, take up as much as half the inner space of the valves (e.g., as seen in many Limnocytherinae).

Juvenile ostracod valves may be specifically indistinct, bearing little resemblance to the adult shape, and mostly possess little or no ornamentation, thus rendering their specific identification almost impossible, unless a monospecific population with adults and juveniles is examined. However, some ostracods display more ornamentation of the valves in juvenile stages, often with much larger and numerous spines being visible at different instar stages, compared to adult valves (see, for examples Diacypris spinosa illustrated in De Deckker 1981a). The common interpretation of this phenomenon is that spinose valves, especially in the earliest instar specimens, may act as deterrent features against potential (micro-) predators. In some cases, this aberrant juvenile morphology has confused ostracod taxonomists, who described them as different species, even in different genera; see for example Eucypris serratomarginata Kiss, 1960, which is the last juvenile stage of Sclerocypris multiformis Kiss, 1960 (discussed in Martens 1986) and Candonocypris serratomarginata Furtos, 1935, which is the juvenile of Chlamydotheca unispinosa (Baird, 1862) (discussed in Martens \& Savatenalinton 2011).

Another important factor, now recognised by aquatic biologists and chemists, is that water composition not only influences the rate of calcification of ostracod valves as mentioned above, but may to some extent affect their ornamentation as well. The level of alkalinity, the $\mathrm{Ca}$ and $\mathrm{HCO}_{3}$ activity of the water in which ostracods grow and form new valves are all particularly relevant when considering valve calcification. This must apply at the time of the formation of a new set of valves, since Turpen \& Angell (1971) showed that no calcium is stored in the ostracod prior to the formation of a new valve.

The extent of valve calcification was recognised by Peypouquet, for instance, when he proposed the concept of valve 'agradation' and 'degradation', aiming at describing the level of calcification, with some valves being over-calcified, resulting in the external ornamentation of some valves being overgrown (see discussion in Carbonel 1988). It is not surprising, therefore, that such a phenomenon 
was recognised by several other researchers who worked in estuaries. Here, water chemistry does vary along the salinity gradient, with continentally-derived waters - frequently rich in humic acids and low in bicarbonate levels - eventually mixing with marine-derived waters that have a higher $\mathrm{pH}$, consist of higher concentrations of bicarbonate and the necessary cations for valve calcification, principally calcium. Carbonel's (1988) classic example in the Mahakam Delta in Borneo shows poorly calcified ostracod valves of Bicornucythere, with an extremely fine ornamentation / reticulation on animals living in humic acid-rich waters in the delta, in contrast to the thicker calcified valves of the same species secreted in the marine realm.

At a finer level, Rosenfeld \& Vesper (1977) have clearly identified the nature of the sieve pores visible on the external side of the (near-) ubiquitous ostracod Cyprideis torosa that display 3 different shapes: round for specimens grown in 'normal' sea water salinity, and irregular (often trilobate) or elongate grown at salinities lower than normal sea water. It is interpreted here that calcification would have been adequate in sea water in which alkalinity levels are high, in contrast to what would normally occur at lower salinities when waters of different origins are mixed together. The circular sieves are considered to be properly formed, whereas the calcification process would be less than adequate at lower alkalinities (and salinities), therefore causing some 'stretching' of the valves during calcification, consequently engendering elongated or irregular sieve pores. Such a 'stretching' phenomenon was observed by Keyser (2005) when he examined node formation on the outer surface of $C$. torosa valves.

\section{Bennelongia - an unusual ostracod genus}

There are about 2000 described species of Recent, non-marine ostracods in the world (Martens et al. 2008; Martens \& Savatenalinton 2011). Half of these, 1000 species, belong to 1 family, the Cyprididae, which comprises more than 20 subfamilies. The most recently described subfamily, the Bennelongiinae Martens et al., 2012, used to comprise 6 species (described in: De Deckker \& McKenzie 1981; De Deckker 1981c, 1982), but recently, 12 new species from Australia were described (Martens et al. 2012; Shearn et al. 2012), bringing the total to 18 described species. However, Martens et al. (2012) announced the existence of several more new species, mostly from Western Australia, some of which will be referred to here.

The first specimens now considered to belong to the genus Bennelongia were collected by King (1855), which he called Cypris bennelong. However, King (1855: 63) stated that it had 'equal valves, sinuous at its ventral edge'. In addition, his illustration (King 1855: fig. A) is too simple to notice the latter written observation. Hence, the species name of bennelong may not be valid, especially since no types have been found and the locality (e.g., 'pond near Sydney Cove, close to the edge of the Saltwater') can no longer be found.

Another species belonging to Bennelongia was collected by Professor Ralph Tate and was described as Chlamydotheca australis by Brady (1886). There is much confusion about the original specimens of the latter species kept at the British Museum and Oslo Museum, where the eminent crustacean expert G. O. Sars left his collection, including a slide sent to him by G. S. Brady (Sars 1896). For further details on the history of confusions about the nomenclatural and taxonomic status of Bennelongia, refer to De Deckker (1981c).

One of the main issues that confronted taxonomists dealing with this lineage has exactly been the morphological discrepancy between juvenile and adults and pre-adult instars (A-1) of a Bennelongia species (originally called Cypris lateraria King, 1855 - see Sars 1896), which was thought to be an adult specimen. For example, the A-1 juveniles have symmetrical valves, have a distinct and well-calcified inner lamella (Figs 1 bottom, 11 bottom, 12 top right, 23 bottom row), and are heavily ornamented with nodes and some reticulation (e.g., Figs 2 centre and bottom rows, 3 all specimens). Adult Bennelongia, 


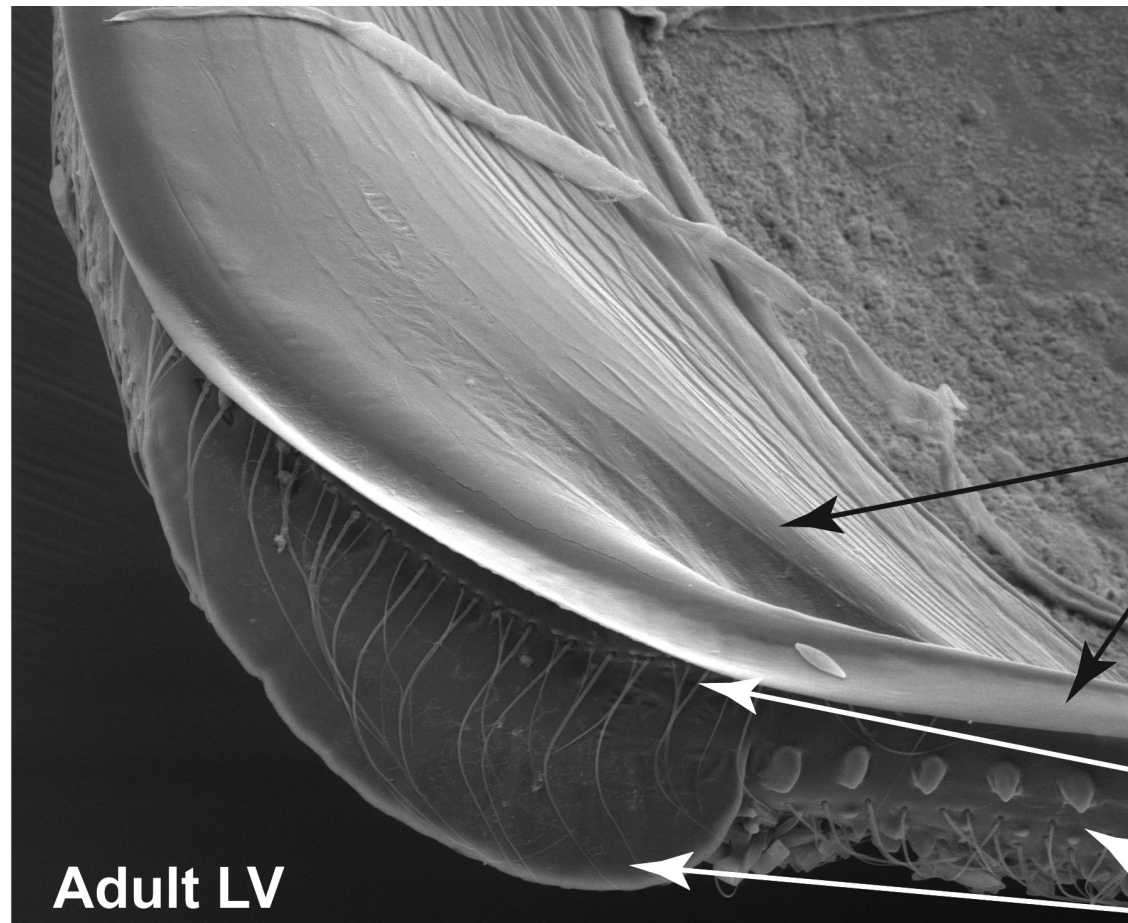

Inner list

Selvage

Valve margin

Flange

Lapel

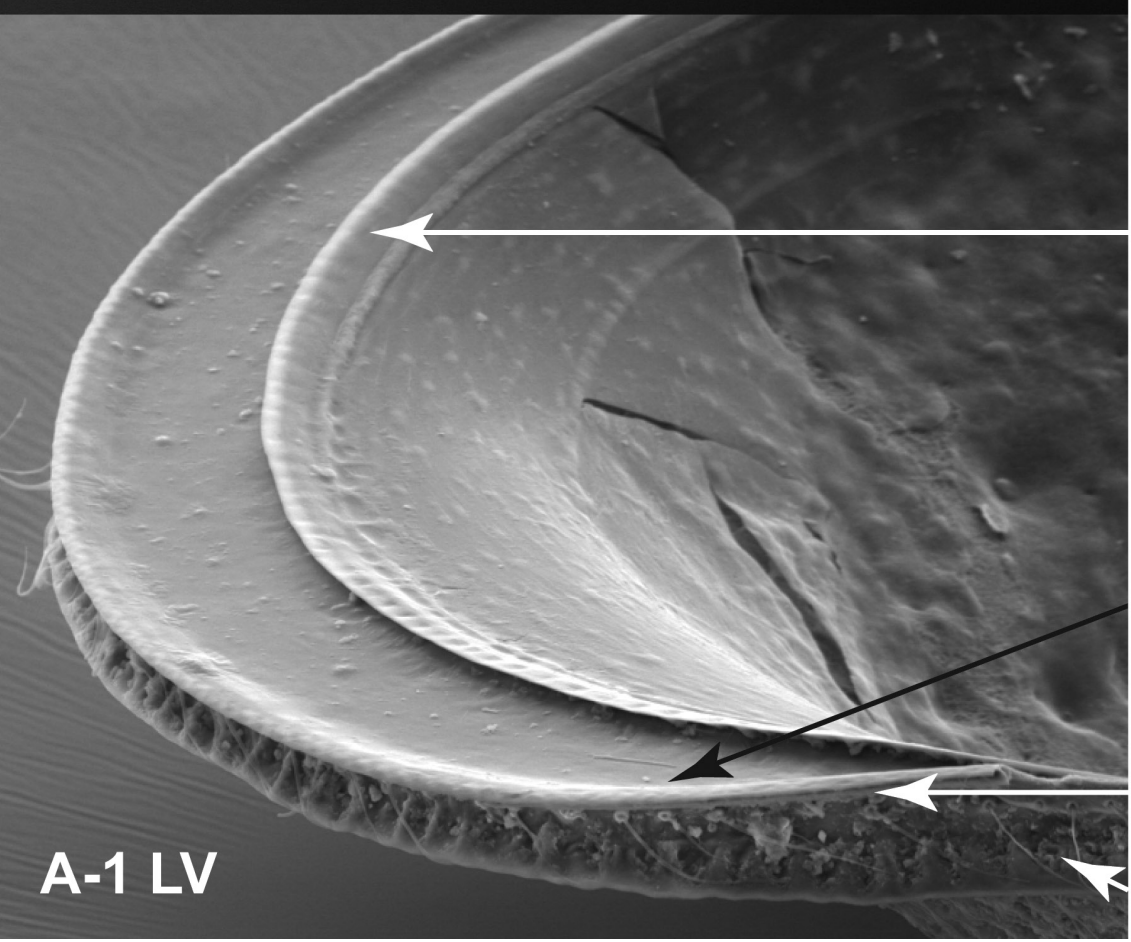

Inner list

Selvage

Valve margin Flange

Fig. 1. SEM photographs showing detailed internal views of the anterior portion of the right valves to highlight key features.

Top: Adult Right valve (=RV) of Bennelongia gwelupensis Martens et al., 2012 from Lake Gwelup, that clearly displays the lapel, characteristic of right valves of Bennelongia adults, which is seen as an extension of the old valve margin. The selvage in this species is very well pronounced.

Bottom: Last instar (=A-1, standing for adult-1 stage) of Bennelongia gwelupensis Martens et al., 2012 from Katanning Road pool. Note the prominent inner list that is rarely seen in A-1 specimens in species of Cyprididae, except in Bennelongia species, and the well calcified selvage replacing the valve margin. 
on the other hand, mostly appear almost smooth externally (Figs 2 top, 11 top left, 13 top left, 14 top left, 16 top left) and have characteristically asymmetrical valves with a beak-like expansion on the antero-ventral region of the left valve (Figs 2 top, 14 and 16 top left in each), which is also larger than the right valve. The calcified inner lamellae in adult valves are very broad, but asymmetrical, especially in the antero-ventral region of the left valve, and also have two prominent inner lists, except where the beak-like rostrum occurs. For ample and labelled illustrations, refer to those in Martens et al. (2012).

A better understanding of the developmental changes in Bennelongia will allow a more accurate identification of species in this genus and will contribute towards our understanding of the processes underlying ostracod ontogeny.

\section{Aims of the present study}

Here, we examine and illustrate the final 3-4 juvenile stages of 6 species, representing 5 distinct lineages, within the genus Bennelongia. Our principal aims have been to:

1. identify and name the main morphological features (e.g., nodes, ridges, pore types etc.) visible on the external side of valves;

2. determine if the features are repeated on both valves of the same specimen;

3. determine if the same features appear consistently during ontogeny and at the same location;

4. determine if these features are consistently present throughout all the Bennelongia species examined;

5. examine the extent and calcified nature of the inner lamella in A-1 specimens of all Bennelongia species we examined.

\section{Material and methods}

The specimens examined for this study and their respective localities are listed in Table 1. Three species have already been formally described, B. gwelupensis Martens et al., 2012, B. kimberleyensis Martens et al., 2012 and B. dedeckkeri Shearn et al., 2012. Three other species are new to science and remain to be formally described. They are named here using monikers (viz. left in open nomenclature).

\begin{tabular}{|c|c|c|c|c|c|c|c|c|}
\hline Species name & $\begin{array}{l}\text { Locality } \\
\text { code }\end{array}$ & Locality name & $\begin{array}{l}\text { Coll. } \\
\text { date }\end{array}$ & Latitude & Longitude & $\begin{array}{c}\mathrm{K} 25 \\
(\mu \mathrm{S} / \mathrm{cm})\end{array}$ & $\begin{array}{l}\text { Temp } \\
\left({ }^{\circ} \mathrm{C}\right)\end{array}$ & pH \\
\hline $\begin{array}{l}\text { Bennelongia cf. } \\
\text { nimala nov. sp. }\end{array}$ & SIKE 20 & Muggon lake & $\begin{array}{l}8 \mathrm{Jul} \\
2011\end{array}$ & $26^{\circ} 44^{\prime} 15^{\prime \prime} \mathrm{S}$ & $115^{\circ} 29^{\prime} 59^{\prime \prime} \mathrm{E}$ & 475 & 13.4 & 8.85 \\
\hline $\begin{array}{l}\text { Bennelongia sp. } 414 \\
\text { nov. sp. }\end{array}$ & SIKE 7 & $\begin{array}{c}\text { CB35a } \\
\text {-Wooramel Stn }\end{array}$ & $\begin{array}{l}5 \text { Jul. } \\
2011\end{array}$ & $25^{\circ} 40^{\prime} 53^{\prime \prime} \mathrm{S}$ & $114^{\circ} 13^{\prime} 17^{\prime \prime} \mathrm{E}$ & 307 & 15.5 & 7.43 \\
\hline $\begin{array}{l}\text { Bennelongia cf. } \\
\text { barangaroo nov. sp. }\end{array}$ & SIKE 9 & McNeil Claypan 2 & $\begin{array}{l}6 \mathrm{Jul} . \\
2011\end{array}$ & $24^{\circ} 52^{\prime} 06^{\prime \prime} \mathrm{S}$ & $113^{\circ} 42^{\prime} 56^{\prime \prime} \mathrm{E}$ & 189 & 10.8 & 9.4 \\
\hline $\begin{array}{l}\text { Bennelongia } \\
\text { dedeckkeri }\end{array}$ & QLDP8A & Lake Dunn & $\begin{array}{l}7 \text { Jun. } \\
2011\end{array}$ & $22^{\circ} 35^{\prime} 42^{\prime \prime} \mathrm{S}$ & $145^{\circ} 41^{\prime} 58^{\prime \prime} \mathrm{E}$ & na & na & na \\
\hline $\begin{array}{l}\text { Bennelongia } \\
\text { kimberleyensis }\end{array}$ & $\begin{array}{c}\text { KIMB } \\
01\end{array}$ & $\begin{array}{c}\text { Taylor's Lagoon, } \\
\text { Broome }\end{array}$ & $\begin{array}{l}21 \mathrm{Jul} . \\
2010\end{array}$ & $17^{\circ} 49^{\prime} 11^{\prime \prime S}$ & $122^{\circ} 41^{\prime} 56^{\prime \prime} \mathrm{E}$ & na & na & na \\
\hline $\begin{array}{l}\text { Bennelongia } \\
\text { gwelupensis }\end{array}$ & DJC 13 & Arro Swamp & $\begin{array}{l}11 \text { Sep. } \\
2011\end{array}$ & $29^{\circ} 44^{\prime} 11^{\prime \prime} \mathrm{S}$ & $115^{\circ} 9^{\prime} 58^{\prime \prime} \mathrm{E}$ & 148 & 17.7 & 5.45 \\
\hline $\begin{array}{l}\text { Bennelongia } \\
\text { gwelupensis }\end{array}$ & DJC 29 & $\begin{array}{l}\text { Katanning } \mathrm{Rd} \\
\text { pool }\end{array}$ & $\begin{array}{l}2 \text { Oct. } \\
2011\end{array}$ & na & na & 354 & 14.9 & 6.4 \\
\hline
\end{tabular}

Table 1. List of species studied here and information on their respective localities. 


\section{SEM photography}

All specimens were kept in 100\% ethanol after collection and remained so until they were dried and used for photography. In most cases, carapaces consisting of 2 valves and with soft parts inside were placed on double sided sticky tape and coated with Au-Pd and photographed with the use of a FEI Quanta ${ }^{\mathrm{TM}}$ 200 Environmental Scanning Electron Microscope (RBINS, Brussels), mostly at 20KV. Photographs displayed here have not been retouched or modified, except in two cases, when we flipped over the image of one of the valves to align it below the other valve from the same specimen to enable better assessment of the location of ornaments (see Figs 9 and 10).

\section{Results}

Class Ostracoda Latreille, 1806

Subclass Podocopa G. W. Müller, 1894

Order Podocopida G.O. Sars, 1866

Suborder Cypridocopina Baird, 1845

Superfamily Cypridoidea Baird, 1845

Family Cyprididae Baird, 1845

Subfamily Bennelongiinae Martens, Halse \& Schön, 2012

Genus Bennelongia De Deckker \& McKenzie, 1981

\section{Remarks}

The following 6 species clearly belong to 5 separate lineages within the genus, and as such form a good representation of juvenile morphologies within the genus. For one species (B. gwelupensis), juveniles of two populations could be compared. Bennelongia dedeckkeri from Queensland and B. cf. barangaroo nov. sp. are so closely related and show such similarity in ontogeny that they are discussed together. They might in fact be the same species, but this will be discussed elsewhere.

\section{Bennelongia cf. nimala nov. sp.}

Figs 2-10

\section{Remarks}

We are describing the last 4 instar stages (A-4 to A-1) of this species first, because, among the taxa we examined, Bennelongia cf. nimala nov. sp., is the species that displays the largest array of morphological features. The subsequent species will be described using the terminology developed for the present species.

\section{Description}

Three major types of 'ornamentation' are clearly visible, going from large to small:

1. The 'dome' is the largest and most prominent feature and lies more or less in the upper central region of the juvenile ostracod valve. It is clearly visible when viewed in a dorsal position (Figs 2, 3). The French word 'coupole' seems to be more suitable to describe this feature, which is faintly reticulated and consists of pseudo-pores (viz. that they do not penetrate through the entire valve) and also bears a normal pore with a seta in its middle (Figs 4,5 ). The dome is not met by a depression inside the ostracod valve and is therefore considered to be an (external) ornamental feature. It is also clear that the type of ornamentation recognised on the dome is not unique to that area, as it appears also on most of the valve (Fig. 5). In some instances, there appears to be a second feature in the shape of a dome, but which is additionally set with 2 to 4 large cones of the types discussed below. This is visible in Fig. 4, Fig. 5, upper left panel, and Figs 7-10. The second domal feature is located posteroventrally to the first dome. 
2. the cones with an outer lip and a seta at their apex. The seta is substantially larger than the one located on the dome. These features are clearly visible in Figures 5 and 6. Such type of conical feature has already been recognised in other ostracods, such as the 'pustules' illustrated by De Deckker (1981b) and Smith \& Martens (1996) near the anterior margin of Eucypris virens, which belongs in Eucypridinae, a family most likely phylogenetically quite close to the Bennelongiinae. It appears that some of the setae penetrate through the entire shell, and could therefore have a different function, as holes are visible inside the carapace of some specimens.

3. the rest of most valves can either be smooth (as seen in the anterior region of the valves) or consist of pseudo-pores (pitted). Nevertheless, normal pores are also present (see Fig. 5, left panel) and are different from the radial pore canals (see van Morkhoven 1962). The juvenile valve surface is pitted, while the adult valves are set with small pustules.

Finally, a clear depression is seen on the outside of the valves posterior to the largest dome (arrowed in Fig. 7). We have been unable to determine whether it is linked with a muscle attachment inside the valve. This feature was not seen in juvenile of other Bennelongia species.

Although the youngest instars (A-4) of $B$. cf. nimala nov. sp. characterisitically display proportionately larger and more obvious ornamentation (Figs 3-4) than the older specimens (A-3 to A-1 instars), the same pattern of nodes, elevated pores and the domes (see description below) are repeated in all juvenile stages. This is best seen in dorsal views of the carapaces (Fig. 3). Note that none of these features are visible in adult specimens as shown in Fig. 2 (top).

Examination of Figs 7 to 10 enabled us to recognise that the domes and conical pores are located mostly at the same sites on both valves in the same instar stages. Many of the cones with pores are arranged either in rows or in clumps. There are some very slight differences between opposite valves, but this could be an artefact of carapace orientation under the SEM when the rounded specimens are stuck on the double-sided sticky tape. Finally, the positioning of the domes and also cones with pores remain similar from one juvenile stage to the other, thus indicating that the placement of these ornaments may be genetically controlled.

In the case of $B$. cf. nimala nov. sp., well over 30 cones with the outer lips and setae have been counted in A-1 specimens and slightly lower numbers were seen in A-4 specimens, but this is not surprising, knowing that the external surface area of the valves of older instar ostracods is much more extensive than for the juvenile ones. Although there were less cones in A-4 than in A-1, they were more pronounced.

We did not examine inner views of juveniles in this species.

Bennelongia sp. 414 nov. sp.

Figs 11-12

This species is in stark contrast with $B$. cf. nimala nov. sp.. First of all, it belongs to the lineage of Bennelongia which is most distant to the other taxa examined in this paper. Also, its general appearance is clearly different from any of the other Bennelongia species thus far described (De Deckker \& McKenzie 1981; De Deckker 1981c, 1982; Martens et al. 2012; Shearn et al. 2012): it is triangular in lateral view and the ventrum is flat and broad (Fig. 11); the antero-ventral beak-like feature in adult LV is absent (Fig. 10) and the instars, at first glance, appear smooth on the outer surface of the valves (Fig. 11).

Close examination of the instars' valve morphology identifies that the 'domes' are definitely present in A-4 to A-1 stages, but are again more obvious in the youngest instar stages (Figs 11-12). The dome that was so prominent in $B$. cf. nimala nov. sp. is a much smaller feature in $B$. spec. 414 nov. sp.. Instead, the posterior dome is the largest of the two and is also reticulated. We assume that the 2 domes occur in the 
same position as in B. cf. nimala nov. sp., and are thus homologous, as the depression seen in the former species is also seen behind what we label as the posterior dome (Fig. 11, middle right panel in A-4, Fig. 12 middle panels) of $B$. sp. 414 nov. sp.

In inner view, the inner lamella is surprisingly broad and well calcified in the A-1 instars. In addition, it has an inner list that is prominent along the entire periphery of the inner lamella, a feature that is prevalent in all Bennnelongia A-1 instars examined here (see also below). This feature is in other cypridid ostracods only present in adult specimens.

Finally, juvenile specimens differ from $B$. cf. nimala nov. sp. juveniles as some cones with outer lips appear to be present (Figs 11-12), but are almost atrophied, and could easily be confused with normal pores with setae.

Bennelongia kimberleyensis Martens, Halse \& Schön, 2012

Figs 13-15

The characteristic 'pinged' depression in the anterior region when seen dorsally is a feature of the 'Bennelongia pinpi'- lineage to which this species belongs (see discussion in Martens et al. 2012). The adult valves are smooth overall, and the A-4 and A-3 instars display a broad reticulation (best seen in A-4; see Figs 13 bottom right, 14 bottom and 15) with some simple pores, that are best described as pseudo-pores in A-2 and A-1 instars.

A few cones with outer lips and setae are common in A-4 and decrease in number and size during the ontogenic progress (see Figs 13-15), but are absent in adults. The 2 sets of domes are obvious in A-4 and less so in A-3, but are absent in older instars and in the adults. When present, the domes are reticulated and are adorned with a seta.

Bennelongia cf. barangaroo nov. sp. Figs 16-18

Bennelongia dedeckkeri Shearn, Koenders, Halse, Schön \& Martens, 2012

Figs 19-21

We examined specimens of $B$. cf. barangaroo nov. sp. from McNeil Claypan in Western Australia and of B. dedeckkeri from Lake Dunn in Queensland. From the former locality, we only had A-1 and A-2, but from the latter we also had specimens of stages A-3 and A-4.

Both species have a very similar appearance and are closely related. Their ontogeny is here discussed together.

The broad morphological characteristics of these species are, in many ways, similar to those of B. gwelupensis Martens et al., 2012 (see below) for the following reasons: pseudo-punctation is visible on the outer surface of the valves in A-1 specimens (Fig. 16 with 8 lateral views), more pronounced reticulation is obvious in A-2 and much more prominent in A-3 specimens (Fig. 17 with dorsal views), although there are areas in the dorsal and postero-dorsal regions which appear smooth, but this may be seen on specimens that were not fully calcified. The domes are somewhat visible in A-2 specimens and more obvious in A-3 specimens (Fig. 16). The cones with outer lips and setae are clearly visible (Fig. 19, middle), but overall these conical features are much fewer than in B. gwelupensis. Nevertheless, the pores penetrate through the entire valves and are seen from the inside (Fig. 18, bottom left). Once again, the inner lamella and selvage are present in A-1 specimens, but not as broad as in B. gwelupensis (see below). 
The pattern in the younger instars remains the same: the valves of younger instars are more reticulated on the outside, the domes appear to be faintly distinguishable in A-1 and A-2 specimens (Figs 18-19) and are much more prominent in A-3 and even more so in A-4 specimens. The domes in these earlier stages appear to be overgrown and display some reticulation that resembles some pseudo-punctation, but may be the result of over-calcification. They also possess the ubiquitous single sieve pores with seta (Fig. 21), also seen in all other species discussed here.

The nature of the reticulation around the domes (Fig. 20) is somewhat puzzling in its arrangement, as it is reminiscent of an irregular meshwork. A better understanding of the process of calcification may help understand how this feature is formed.

Once again, the domes differ in size (Fig. 21), and in these species, the posterior one is the largest of the two.

The pseudo-punctation is obvious in A-1 and A-2 specimens but would have replaced the reticulated nature of the outer valves as seen in A-3 and A-4 (Fig. 20). The cones are present especially near the anterior and posterior margins of the valves, but are definitely not abundant. In the vicinity of the domes, the cones are quite small, but retain their outer lip (Fig. 21).

Bennelongia gwelupensis Martens, Halse \& Schön, 2012

Figs 22-24

Specimens of B. gwelupensis were chosen from 2 different localities (DJC13, Arro Swamp: Fig. 22, and DJC 29, Katanning Rd pool: Fig. 23) so as to determine whether there may be some morphological differences in valve ornamentation between sites. This species belongs to the Bennelongia australis lineage (see discussion in Martens et al. 2012).

Unfortunately, we were unable to get A-3 and A-4 instars of this species from either locality, but it is evident that the 2 domes are present at least in the A-2 specimens, while only the posterior one is visible in A-1 specimens (Figs 22, 23). What is striking, nevertheless, is the pseudo-punctation in juvenile stages, and the presence of a large number of cones with outer lips and setae. Well over 30 of these are seen in both valves, and they are more prominent at the A-2 stage (Fig. 22). Comparison between A-1 specimens from the 2 localities (Figs 22-23) shows that the location of the cones on the valves are very similar, and this again points to a genetic determination of their placement; they are not controlled by water chemistry.

Finally, the broad and calcified inner lamella with the inner list is present in A-1 juveniles (Fig. 23 bottom right). We dissected some further A-1 specimens of this species, and could confirm that the soft parts are typical of an A-1 juvenile, i.e., undeveloped reproductive organs and A2 with $4+1$ natatory setae $(5+1$ setae occur in adult Cyprididae).

\section{Discussion}

\section{General patterns of external valve morphology through ontogeny}

The present descriptions of the valves of juvenile specimens of six species in the genus Bennelongia confirm earlier reports on the large discrepancy between external valve morphologies in juveniles and adults (De Deckker 1981c). They also make it easier to understand why early researchers failed to see the conspecificity of these different stages in the same life cycle (see introduction). Based on the above descriptions, we can reach the following conclusions. 
Whereas the structure of the valve margin changes abruptly, from fairly symmetrical to very asymmetrical in a single moult (the last one), the change from heavily ornamented valves to (almost) smooth valves is a gradual process that occurs over 3-4 moults. The ornaments that are very conspicuous in stage A-4 have all but disappeared in A-1 and then fully in the adult stage. Adults can have some remnants of the juvenile ornamentation, for example adults of Bennelongia $\mathrm{cf}$. nimala nov. sp. seem to have 1-2 remnants of the numerous juvenile cones, but in general, the ornamentation in this species has even completely inverted, the numerous pits in the juvenile stages are replaced by a pustulose surface set by wart-like knobs (see Fig. 2).

We have also shown that the general pattern of external morphology is the same between right and left valves (Fig. 4) and that the positions of the various structures remain recognisable between the different juvenile stages; they only disappear (almost) completely in the last moult to the adult stage (see Figs 7-10). The same feature was recognised by Kilenyi (1972), who investigated the position of nodes in the ubiquitous ostracod Cyprideis torosa (Jones, 1850).

The patterns of changes of external valve morphology through the final stages of ontogeny are quite different in the five investigated lineages of Bennelongia, even to the extent that it might be required to attach a more formal nomenclatural status to these lineages, with diagnoses based on the ontogeny. Whereas $B$. cf. nimala nov. sp. shows the combinations of the dome and groups of cones, together with pitted surface, in the last 4 juvenile stages (Figs 2-10), B. sp. 414 nov. sp. shows only part of these structures (although the dome remains well-recognisable) and the valve surface itself is almost smooth, not pitted (Fig. 11). Bennelongia kimberleyensis has some dome- and cone-like structures, but the valve surface in A-4 is strongly crested, pitted in stages A-3 to A-1 and smooth in adults. The crested valve ornament was also illustrated for early juveniles of $B$. pinpi by De Deckker (1981c: fig 12o), which makes sense as $B$. pinpi and B. kimberleyensis belong to the same lineage within Bennelongia (Shearn et al. 2012). Also in Bennelongia cf. barangaroo nov. sp. and B. dedeckkeri, the A-3 (Fig. 17) and especially the A-4 (Fig. 18) show some crest-like sculptures, but here the dome is less well-developed.

Nevertheless, these species display another interesting feature: all juvenile stages clearly show anterior and posterior cones, which appear to be homologous with the Porenwarzen that were thought to be typical of the genus Eucypris, and which are clearly visible in the type species of the genus, E. virens (see illustrations in De Deckker 1981a and Smith \& Martens 1996). In Bennelongia cf. barangaroo nov. sp. and $B$. dedeckkeri, these Porenwarzen have completely disappeared in the adult, but in adult $E$. virens they are still present. In the ontogeny of the latter species, these Porenwarzen appear in A-5/A-4 and become more prominent in later stages (Smith \& Martens 2000). Bennelongia $\mathrm{cf}$. barangaroo nov. sp. and $B$. dedeckkeri show the opposite development. Bennelongia gwelupensis, finally, shows a similar development to that of $B$. cf. barangaroo nov. sp., with many Porenwarzen (and a very weak dome) in the juveniles, and none of these structures in the adult.

Adults of Bennelongia species invariably have a field of small, knob-like structures near the anteroventral part of the right valve. The function of these structures remains unclear, but they occur in all lineages of the genus (Martens et al. 2012). None of the juvenile stages investigated here show these structures, so that they must also appear during the last moult, together with the pronounced asymmetry of the anterior part of the carapace.

Finally, juveniles of species in the Cyprididae almost invariably have a narrow calcified (anterior) inner lamella, without special structures attached to them. Juveniles, especially A-1, of the different species of Bennelongia have a relatively wide calcified inner lamella, especially anteriorly, with a well-developed inner list (see for example Figs 1, 11, 12, 23, 24). This appears to be an adult structure and might be the result of a heterochronic process. It is possible that the change from the fully juvenile valve margin 
to the highly developed and asymmetrical adult anterior valve margin is not possible in one moult, and that therefore such an intermediate stage is necessary. Through heterochronic processes, such an intermediate stage (which is similar to that of the RV in the closely related genus Heterocypris) of an ancestral form could have been preserved or even be added through a process known as intercalation. Some indication of that can be found in the fact that species of Bennelongia with the least well-developed beak in the LV (B. sp. 414 nov. sp.) also has the least developed anterior inner list in the A-1 (Fig. 11 bottom). In such species, the intermediate stage might be less needed. It is possible that valves in A-1 stages heterochronically develop (partial) adult features, while the rest of the valves and the soft parts remain entirely juvenile. Danielopol et al. (1990) already discussed the fact that different limbs, and even different parts of limbs, can follow independent developmental strategies, so the same could be true for valves.

\section{Function of the juvenile valve ornamentation}

Horne \& Smith (2004: plate 2) described some juvenile stages of the cypridopsine species Potamocypris humilis (Sars, 1924) from Great Britain. This species has a similar discrepancy between the valve morphology of juveniles and that of adults and also here a dome and groups of cones can be recognised, although the dome is situated more anteriorly, and might thus not be fully homologous with that of Bennelongia species. Also here, dome and cones progressively diminish in ontogeny and are absent in the adult. The crested morphology of early juvenile stages gradually disappears and changes to a fully pitted surface in the adults in P. humilis. The similarity of the ontogenetic processes in valve ornamentation between this cypridopsine species and some of Bennelongia is all the more striking, as the subfamily Cypridopsinae Kaufmann, 1900 are phylogenetically only distantly related to the Bennelongiinae. Either this dissimilarity in valve ornamentation throughout ontogeny is an ancestral process, retained in some ostracod lineages and lost in others, or this is an example of convergent evolution. In both cases, one would suspect adaptational advantages in functionality.

The problem is, of course, that we can only speculate about such possible functions. There are few papers describing the ontogeny of non-marine ostracods (see overview in Smith \& Martens 2000; and add Smith \& Kamiya 2005 on Uncinocythere occidentalis Kozloff \& Whitman, 1954, and Smith \& Kamyia 2008 on two darwinulid species). Most of these papers concentrate especially on the development of soft parts and pay little attention to valve development, although at least in the latter two papers, valves of juveniles and adults were completely smooth.

The function of the dome is the least clear. It cannot be related to vision, as it is situated too much posteriorly from the position of the eye. This is certainly so in Bennelongia, where it is situated almost in the centre of the valves, but even in the case of Potamocypris humilis where it is more anteriorly situated (Horne \& Smith 2004), the dome does not coincide with the internal eyes.

For the cones, one could suggest that the apical setae could be erected during moulting, to help eject the old valves. This would be more efficient in earlier juvenile stages, with smaller and lighter valves, than in the later juvenile stages, with larger and heavier valves, so cones gradually disappear as ontogeny progresses. As ostracods have determinate growth, there are no more moults when the adult stage is reached, so the adults do not need cones. This matches the situation in Bennelongia, but then why adults of Eucypris virens have retained these cones (as Porenwarzen) is unclear.

Larval and juvenile stages in animals are often dispersal stages (Williamson 2003). Would the stronger valves allow protected passage through the gut of birds and fish, or would the ornamentation allow easier attachment to potential vectors? Lopez \& Rios (2001) demonstrated that ostracods from phytothelmata can be dispersed, attached to the skin of Amphibia, although the particular ostracod species in that study (belonging to Candonopsis s.l.), admittedly had fully smooth valves. However, species of Bennelongia 
also live in temporary habitats (see habitat descriptions in De Deckker 1981a; Martens et al. 2012; Shearn et al. 2012) and thus need a variety of dispersal strategies.

Other possibilities may include improved buoyancy on soft sediments.

One factor we are certain of is that the ornamentation of the juveniles is unrelated to sexual selection, as these features disappear as soon as the reproductive stage is reached.

Finally, it is also possible that there is no obvious function, and that domes and cones are errors in development, much like it was demonstrated for the nodes in Cyprideis torosa (see Keyser 2005), although for the origin of nodes in that species, a salinity-related, causal mechanism was described, which would not be applicable for the obligate freshwater species of the genus Bennelongia.

Speculation aside, only experimental set-ups will be able to test the above hypotheses, and these are beyond the scope of the present paper.

\section{Acknowledgements}

We wish to thank the following people who provided collections used in this study: Rylan Shearn (Edith Cowan University), Jane McRae and Stuart Halse (Bennelongia Pty Ltd). Julien Cillis was instrumental in taking all the outstanding SEM photographs and Kristiaan Hoedemakers assembled the final plates and we wish to acknowledge his superb skills. We thank Stuart A. Halse and Rylan Shearn (Perth) for very useful comments.

KM acknowledges the financial support of ABRS grant (RF211-33: Biodiversity and taxonomy of Ostracoda (Crustacea) from temporary water bodies of inland Western Australia).

\section{References}

Benson R.H. \& MacDonald H.C. 1963. Postglacial(Holocene) ostracodes from Lake Erie.Paleontological contributions of the University of Kansas 33 (Arthropoda 4): 1-26.

Brady G.S. 1886. Notes on the freshwater Entomostraca from South Australia. Proceedings of the Zoological Society of London 54: 82-93.

Carbonel P. 1988. Ostracods and the transition between fresh and saline waters. In: De Deckker P., Colin J.P. \& Peypouquet J. P. (eds) Ostracoda in the Earth Sciences: 157-173. Elsevier, Amsterdam.

Chivas A.R., De Deckker P. \& Shelley J.M.G. 1983. Magnesium, strontium, and barium partitioning in nonmarine ostracode shells and their use in palaeoenvironmental reconstructions - a preliminary study. In: Maddocks R.F. (ed.) Applications of Ostracoda: 238-249. University of Houston, Geoscience Department, Houston.

Danielopol D.L., Martens K. \& Casale L.M. 1990. Revision of the genus Leucocythere Kaufmann, 1892 (Crustacea, Ostracoda, Limnocytheridae), with the description of a new species and two new tribes. Bulletin van het Koninklijk Belgisch Instituut voor Natuurwetenschappen, Biologie 59 (1989): 63-94.

De Deckker P. 1981a. Ostracoda from Australian inland waters - Notes on taxonomy and ecology. Proceedings of the Royal Society of Victoria 93: 43-85.

De Deckker P. 1981b. Taxonomic Notes on Some Australian Ostracods with Description of New Species. Zoologica Scripta 10: 37-55. http://dx.doi.org/10.1111/j.1463-6409.1981.tb00483.x

De Deckker P. 1981c. Taxonomy and ecological notes of some ostracods from Australian inland waters. Transactions of the Royal Society of South Australia 105 (3): 91-138. 
De Deckker P. 1982. On Bennelongia tunta De Deckker sp.nov. A Stereo-Atlas of Ostracod Shells 9 (21): 117-124.

De Deckker P., Geurts M.A. \& Julia R. 1979. Seasonal rhythmites in a Lower Pleistocene lake in NE Spain. Palaeogeography, Palaeoclimatology, Palaeoecology 26: 43-71. http://dx.doi.org/10.1016/0031$\underline{0182(79) 90140-8}$

De Deckker P. \& McKenzie K.G. 1981. Bennelongia, a new cyprididid ostracod from Australasia. Transactions of the Royal Society of South Australia 105: 53-58.

Halse S.A., Shiel R.J., Storey A.W., Edward D.H.D., Lansbury I., Cale D.J. \& Harvey M.S. 2000. Aquatic invertebrates and waterbirds of wetlands and rivers of the southern Carnarvon Basin, Western Australia. Records of the Western Australian Museum, Supplement 61: 217-265.

Horne D.J. \& Smith R.J. 2004. First British record of Potamocypris humilis (Sars, 1924), a freshwater ostracod with a disjunct distribution in Europe and southern Africa. Bollettino della Società Paleontologica Italiana 43 (1-2): 297-306.

Kesling R.V. 1951. The morphology of ostracod molt stages. Illinois Biological Monographs 21: 1-324.

Keyser D. 2005. Histological peculiarities of the noding process in Cyprideis torosa (Jones) (Crustacea, Ostracoda). Hydrobiologia 538: 95-106. http://dx.doi.org/10.1007/s10750-004-4940-x

Kilenyi T.I. 1972. Transient and balanced genetic polymorphism as an explanation of variable nodding in the ostracode C. torosa. Micropaleontology 18: 47-63.

King R.L. 1855. On Australian Entomostracans. Papers and Proceedings of the Royal Society of Van Diemen's Land 3 (1): 56-75.

Lopez L.C.S. \& Rios R.I. 2001. Phytotelmata community distribution in tanks of shaded and sunexposed terrestrial bromeliads from restinga vegetation. Selbyana 22: 219-224.

Martens K. 1985. Effects of temperature and salinity on postembryonic growth in Mytilocypris henricae (Crustacea, Ostracoda). Journal of Crustacean Biology 5 (2):258-272. http://dx.doi.org/10.2307/1547873

Martens K. 1986. Taxonomic revision of the subfamily Megalocypridinae Rome, 1965 (Crustacea, Ostracoda). Verhandelingen van de koninklijke Academie voor Wetenschappen, Letteren en Schone Kunsten, Klasse der Wetenschappen 48 (174): 1-81.

Martens K., Schön I., Meisch C. \& Horne D.J. 2008. Global biodiversity of non-marine Ostracoda (Crustacea). In: Balian E., Segers H. \& Martens K. (eds) Freshwater animal diversity assessment. Hydrobiologia 595: 185-193. http://dx.doi.org/ 10.1007/s10750-007-9245-4

Martens K. \& Savatenalinton S. 2011. A subjective checklist of the Recent, free-living, non-marine Ostracoda (Crustacea). Zootaxa 2855: 1-79.

Martens K., Halse H. \& Schön I. 2012. Nine new species of Bennelongia De Deckker \& McKenzie, 1981 (Crustacea, Ostracoda) from Western Australia, with the description of a new subfamily. European Journal of Taxonomy 8: 1-56. http://dx.doi.org/10.5852/ejt.2012.8

Rosenfeld A. \& Vesper B. 1977. The variability of the sieve-pores in recent and fossil species of Cyprideis torosa (Jones, 1850) as an indicator for salinity and palaeosalinity. In: Löffler H. \& Danielopol D.L. (eds), Aspects of Ecology and Zoogeography of Recent and Fossil Ostracoda: 55 -67. Junk, The Hague.

Sars G.O. 1896. On fresh-water Entomostraca from the neighborhood of Sydney, partly raised from dried mud. Archiv for Mathematik og Naturvidenskab 18 (3): 1-81. 
Shearn R., Koenders A., Halse S., Schön I. \& Martens K. 2012. A review of Bennelongia De Deckker \& McKenzie, 1981 (Crustacea, Ostracoda) species from eastern Australia, with the description of three new species. European Journal of Taxonomy 25:1-35. http://dx.doi.org/10.5852/ejt.2012.25

Smith R.J. \& Martens K. 1996. On Eucypris virens (Jurine). Stereo-Atlas of Ostracod Shells 23 (14): 61-68.

Smith R.J. \& Martens K. 2000. The ontogeny of the cypridid ostracod Eucypris virens (Jurine, 1820) (Crustacea, Ostracoda). Hydrobiologia 419: 31-63. http://dx.doi.org/10.1023/A:1003985908460

Smith R.J. \& Kamyia T. 2005. The ontogeny of the entocytherid ostracod Uncinocythere occidentalis (Kozlov \& Whitman, 1954) Hart, 1962 (Crustacea). Hydrobiologia 538: 217-229. http://dx.doi. org/10.1007/s10750-004-4965-1

Smith R.J. \& Kamyia T. 2008. The ontogeny of two species of Darwinuloidea (Ostracoda, Crustacea). Zoologischer Anzeiger 247: 275-302. http://dx.doi.org/10.1016/j.jcz.2008.05.002

Turpen J.B. \& Angell R.W. 1971. Aspects of molting and calcification in the ostracode Heterocypris. Biological Bulletin of the Marine Biology Laboratory 140: 331-338.

Van Morkhoven F.P.C.M. 1962. Post-Palaeozoic Ostracoda. Volume 1. Their Morphology, Taxonomy, and Economic Use. Elsevier Publishing Company, Amsterdam.

Williamson D.I. 2003. The origins of larvae. Kluwer Academic Publishers, Dordrecht, 261 pp.

Manuscript received: 12 November 2012

Manuscript accepted: 25 January 2013

Published on: 31 January 2013

Topic editor: Rudy Jocqué

Desk editor: Kristiaan Hoedemakers

Printed versions of all papers are also deposited in the libraries of the institutes that are members of the EJT consortium: Muséum National d'Histoire Naturelle, Paris, France; National Botanic Garden of Belgium, Meise, Belgium; Royal Museum for Central Africa, Tervuren, Belgium; Natural History Museum, London, United Kingdom; Royal Belgian Institute of Natural Sciences, Brussels, Belgium; Natural History Museum of Denmark, Copenhagen, Denmark. 


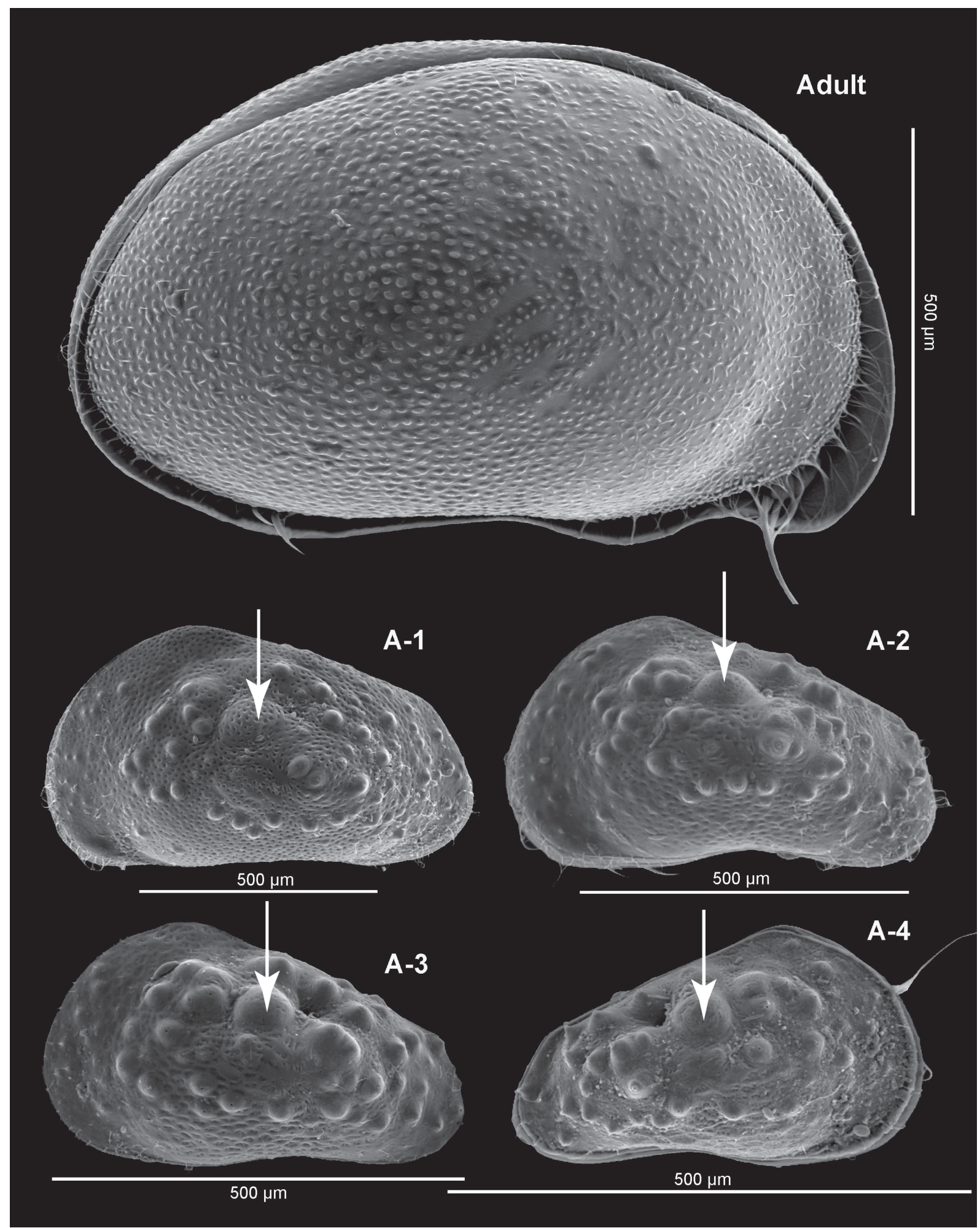

Fig. 2. External lateral views of Bennelongia cf. nimala nov. sp. from Muggon Lake. Top. adult carapace in right lateral view. Note the pronounced asymmetry of the valves, especially in the anterior region. Middle. LV of A-1 and A-2 specimens. Bottom. LV of A-3 specimen and RV of A-4 specimen. Domes are arrowed. 


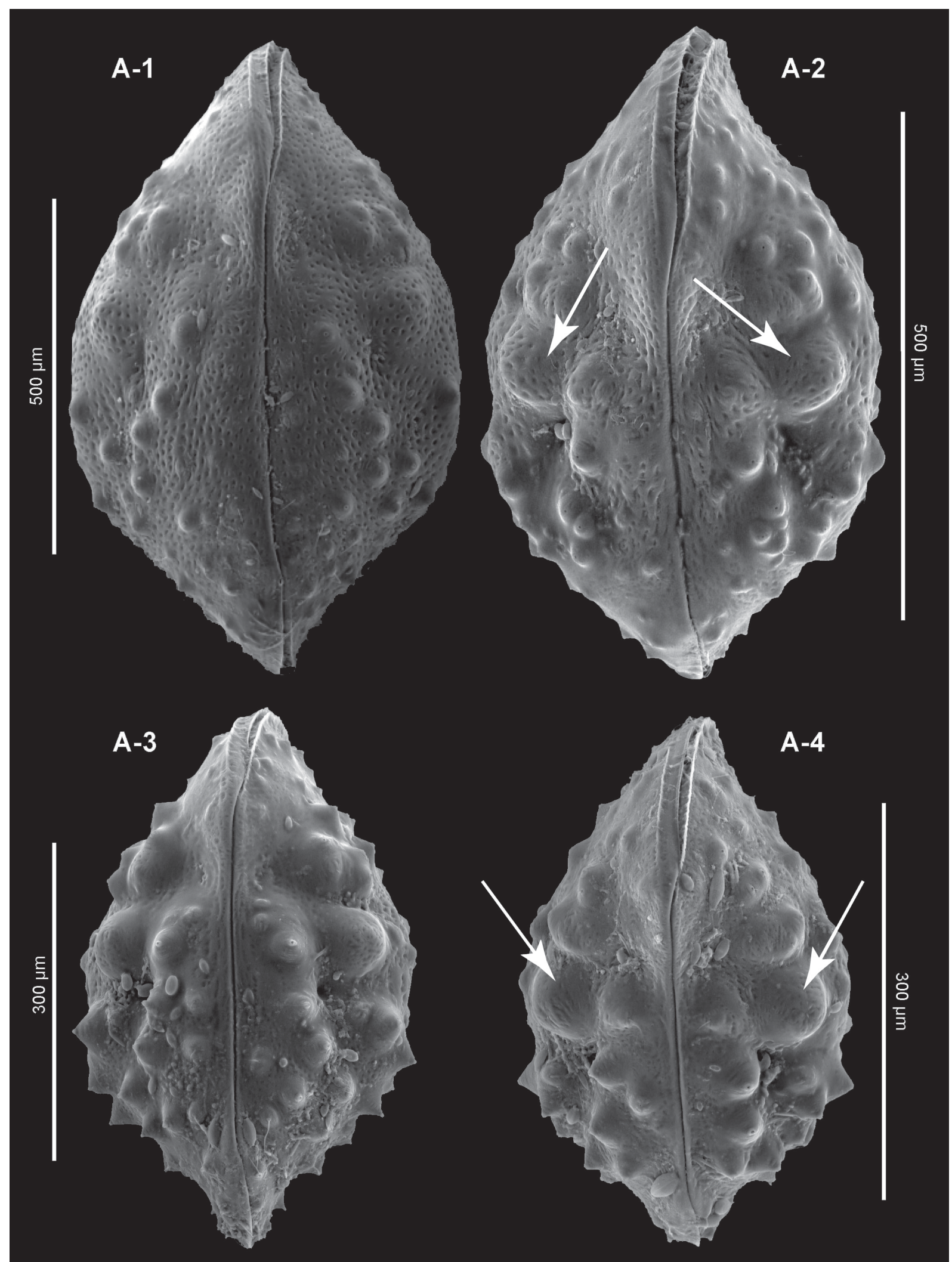

Fig. 3. External dorsal views of juvenile carapaces (A-1 to A-4) of Bennelongia cf. nimala nov. sp. from Muggon Lake. Domes are arrowed. 


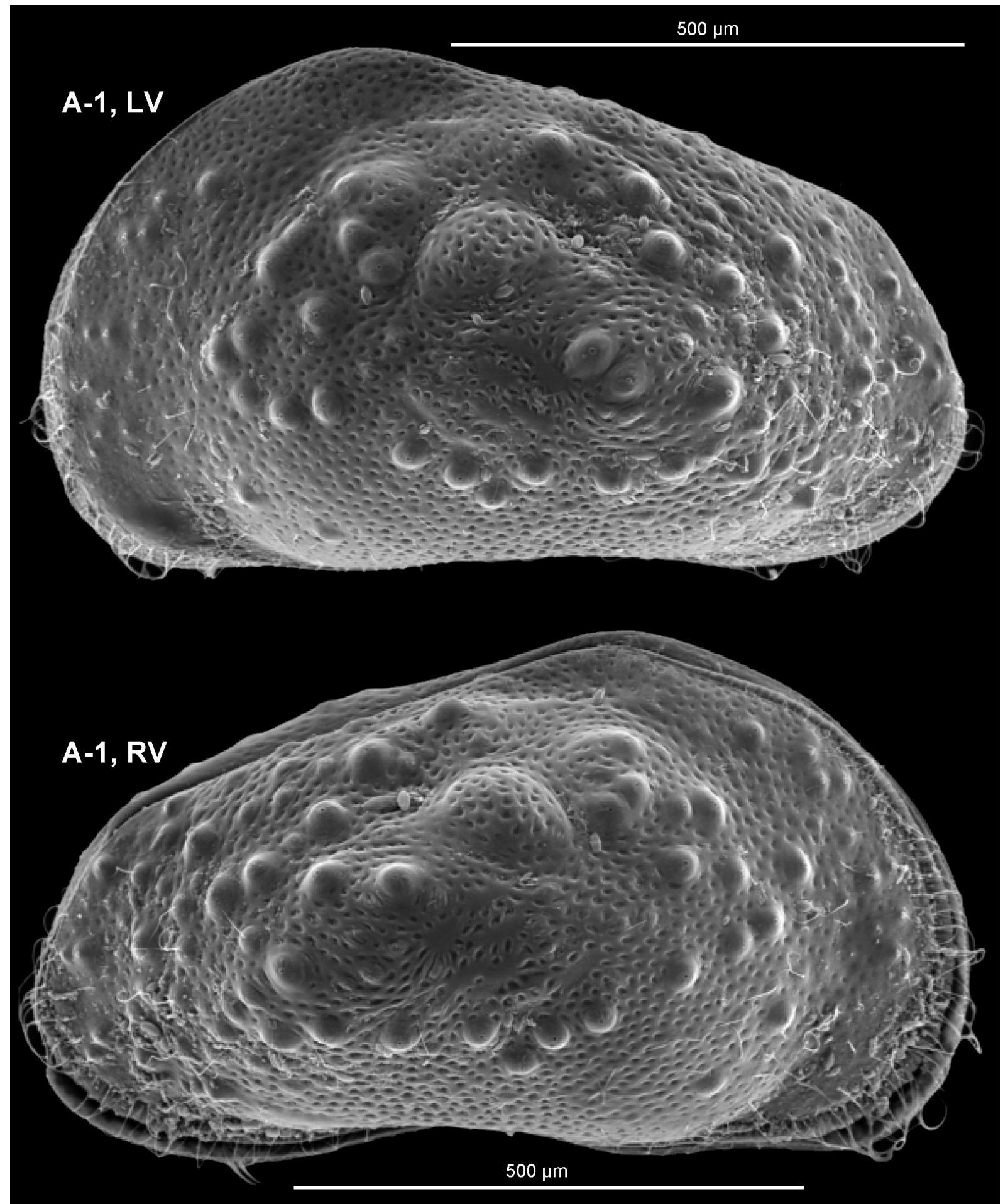

Fig. 4. Lateral external views of carapaces of A-1 juveniles of Bennelongia cf. nimala nov. sp. from Muggon Lake. Top in left lateral view and bottom in right lateral view. 


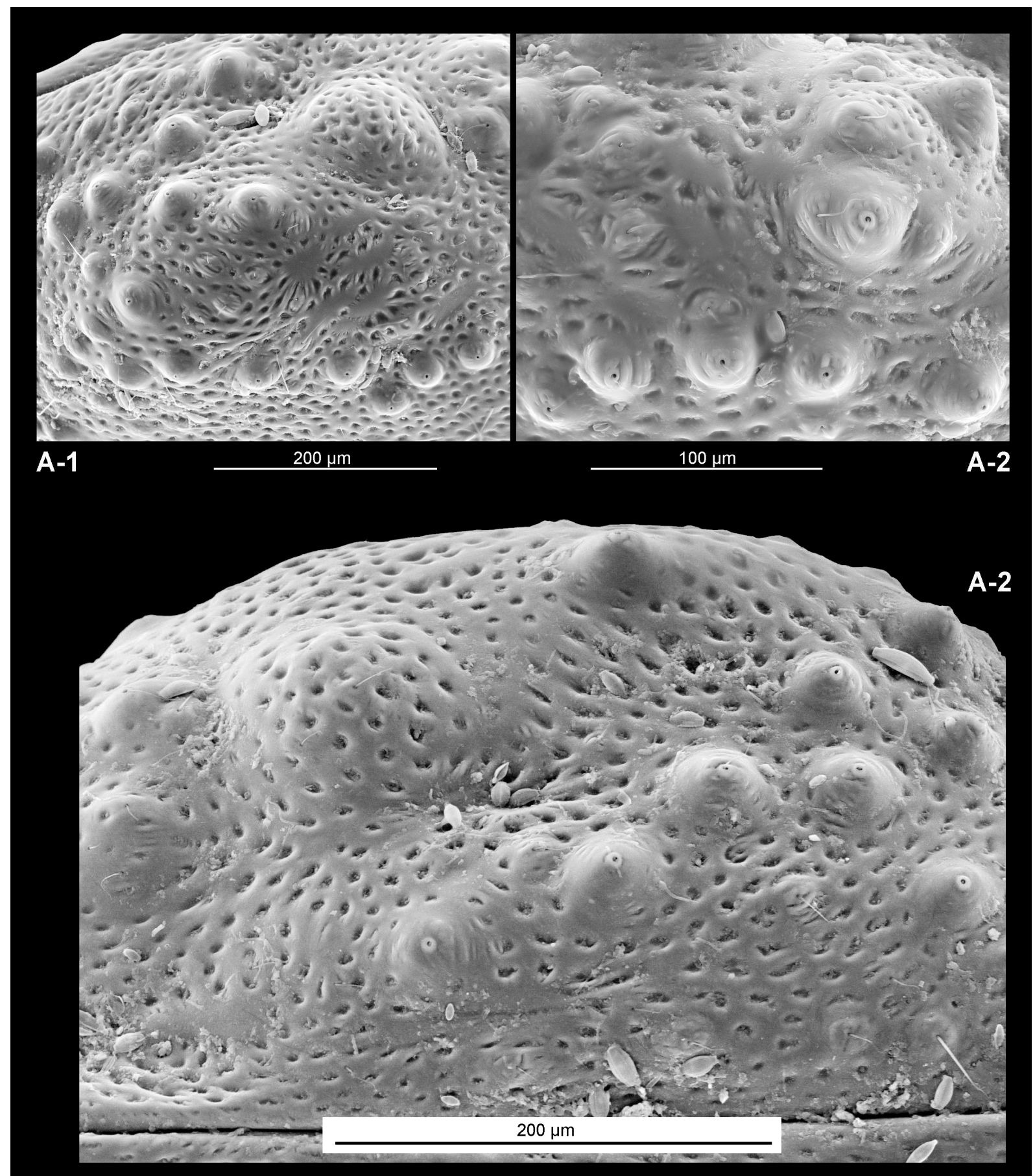

Fig. 5. Details of external lateral views of carapaces of Bennelongia cf. nimala nov. sp. juveniles from Muggon Lake. Top left. A-1 showing the dome and many of the cones with outer lips. Note the large pseudo-pores that are elongated over what appears to be a second protuberance. Top right. A-2 showing the cones with the outer lips at their apex. Many of the pores yield a seta. Bottom. RV of A-2 in dorsal view, showing the assemblage of cones with outer lips and the dome, on top of which a seta occurs. Note the hinge at the bottom. 


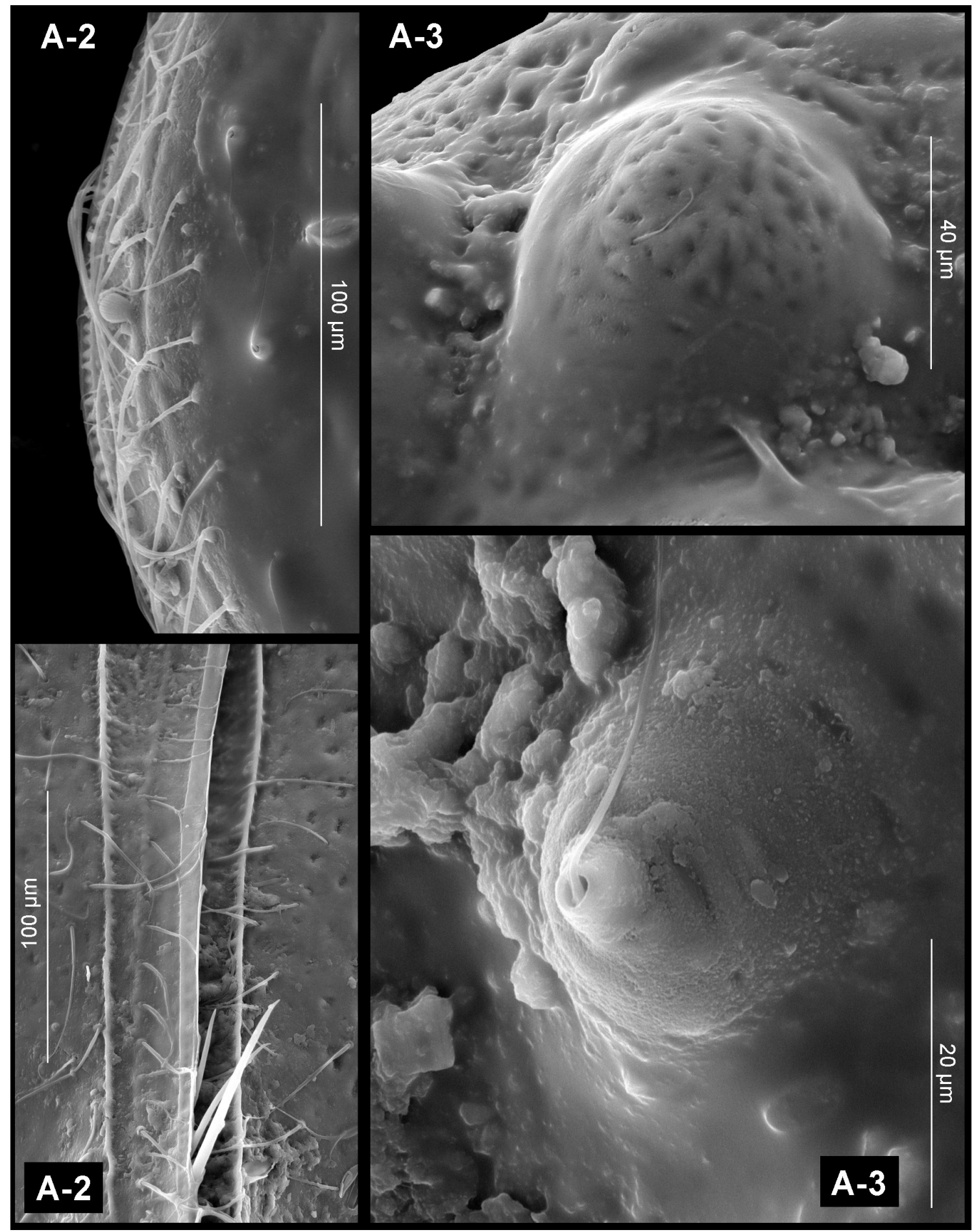

Fig. 6. Details of external views of carapaces of Bennelongia cf. nimala nov. sp. juveniles from Muggon Lake. Top left. anterior margin of A-2 carapace in left lateral view, showing the arrangement of the radial pores and their setae. Top right. enlargement of the cone of A-3 valve, showing the fine seta near its top. Bottom left. ventral view of the two valves, showing the radial pores and setae as well as the very fine and narrow external flange in both valves, but more pronounced in the RV seen on the left here. Note also that claws of some limbs are protruding from the closed valves. Bottom right. enlargement of cone and associated lip and protruding seta of an A-3 specimen. Note the presence of fine particulate material stuck to the valve. 


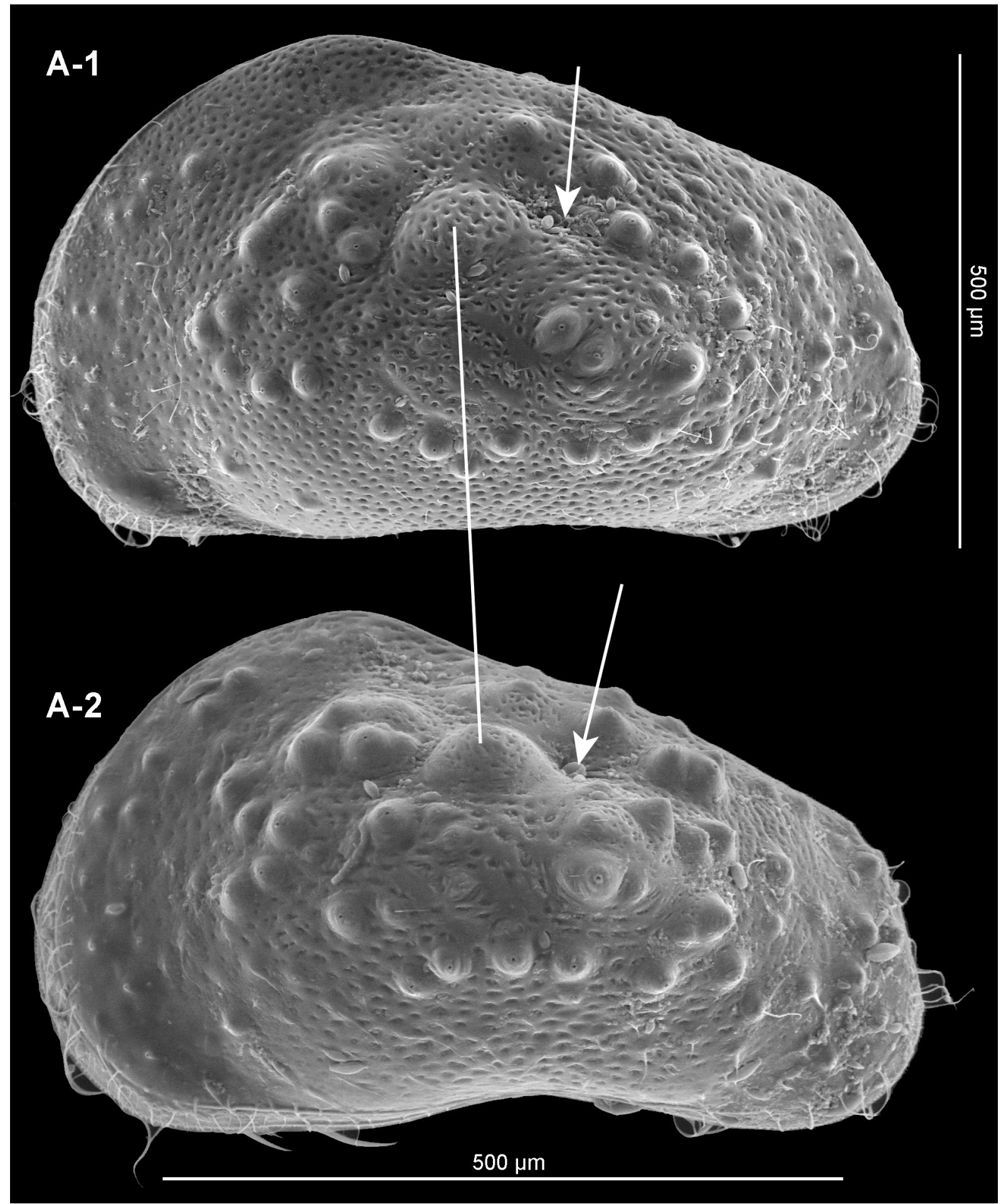

Fig. 7. External views of carapaces of Bennelongia cf. nimala nov. sp. juveniles from Muggon Lake, showing left valves in order to compare the ornamentation between an A-1 specimen (top) and A-2 specimen (bottom). The arrows indicate a clear depression postero-dorsally to each dome, that are linked by a white line. 


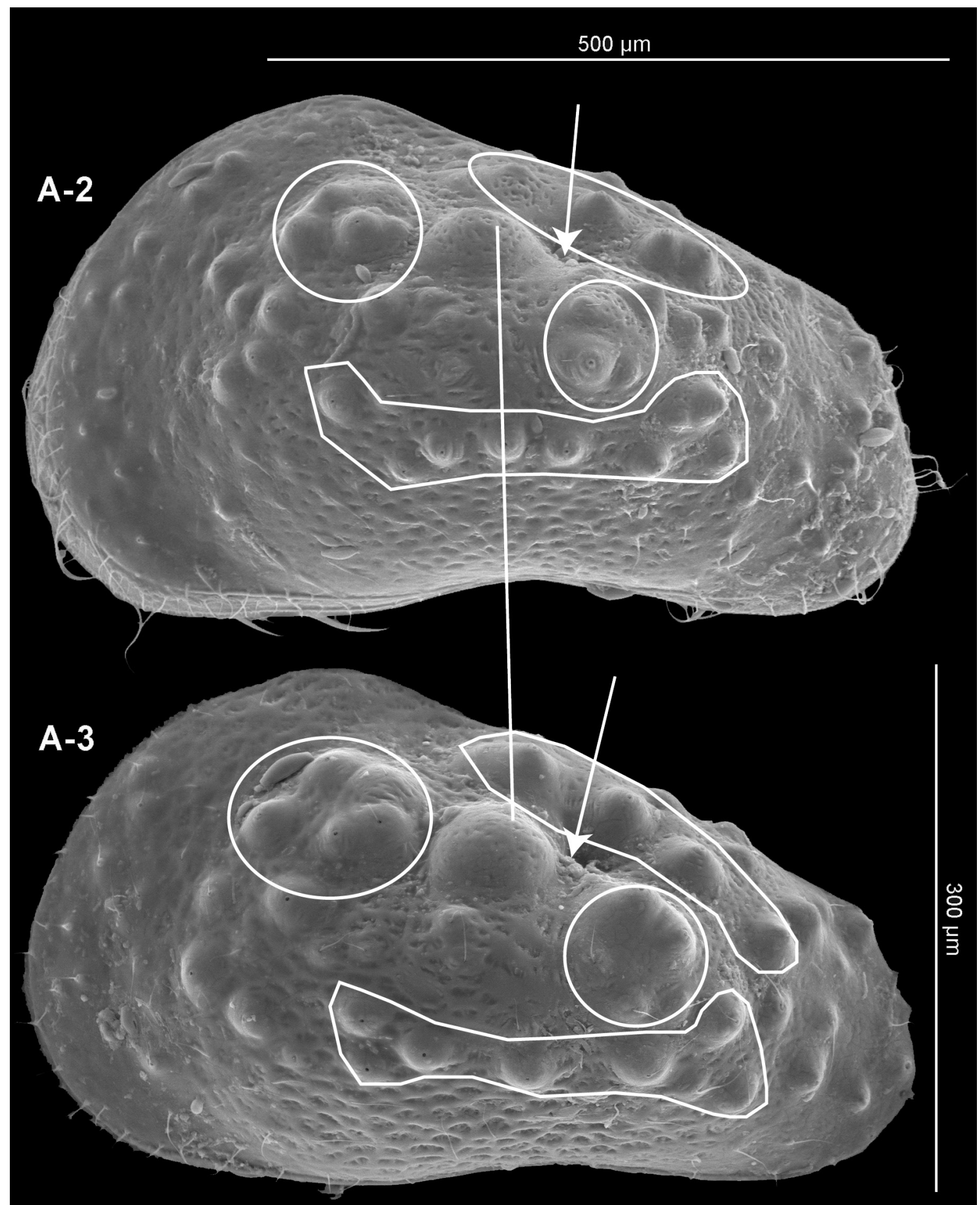

Fig. 8. External views of carapaces of Bennelongia cf. nimala nov. sp. juveniles from Muggon Lake, showing left valves in order to compare the ornamentation between an A-2 specimen (top) and A-3 specimen (bottom). The circles, ellipses and polygons are used to define the ornamentations that are common to both specimens. The arrows indicate a clear depression, postero-dorsally to each dome, that are linked by a white line. 


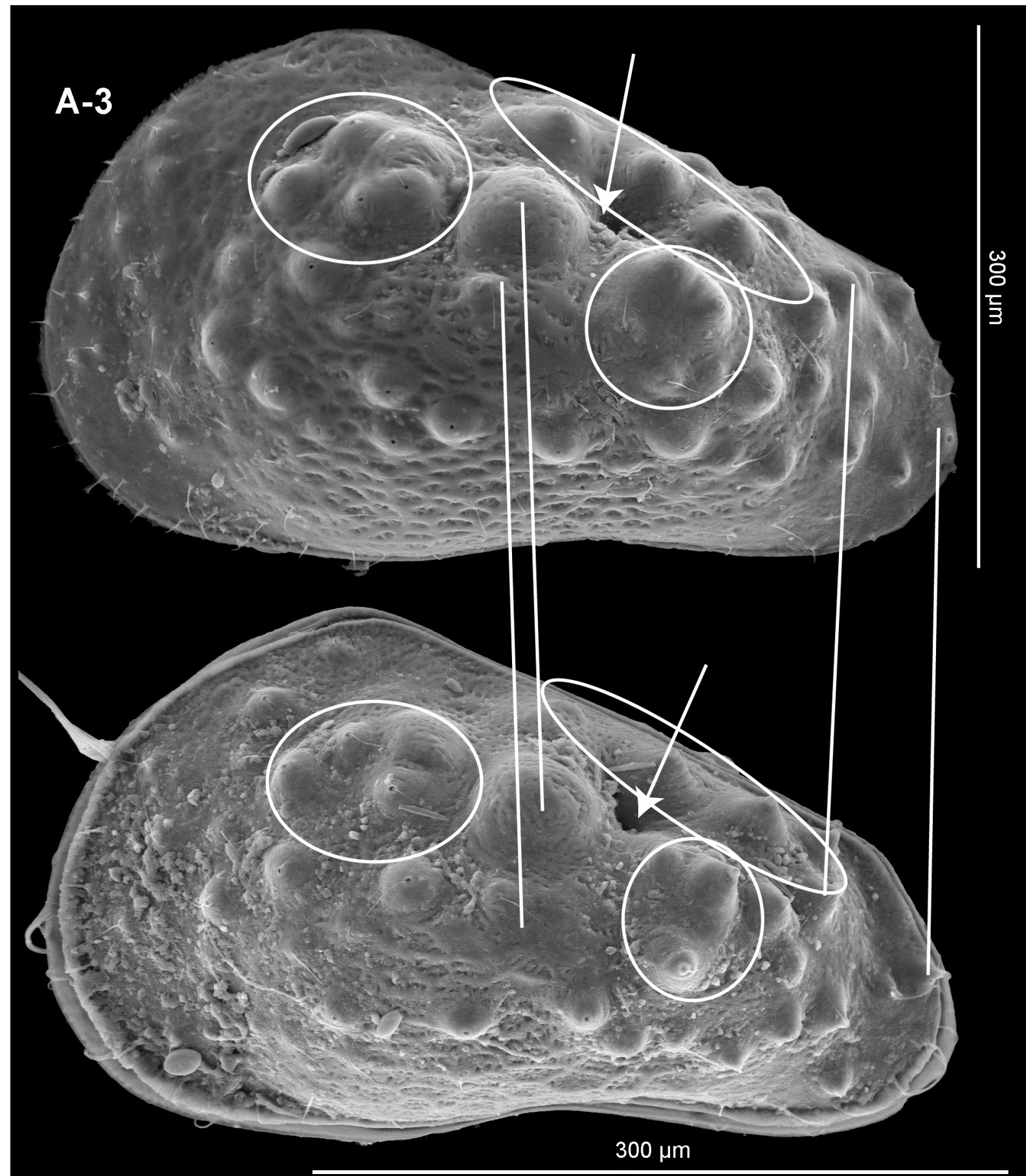

\section{A-4 RV, flipped over}

Fig. 9. External views of carapaces of Bennelongia cf. nimala nov. sp. juveniles from Muggon Lake. The top image shows an A-3 left valve, whereas the bottom image shows a RV of an A-4 specimen that has been 'flipped over' digitally, so as to permit comparison of the type of external ornamentation and respective location. The white lines (straight as well as circles and ellipses) permit direct comparison between features. Note the presence of particulate matter as well as diatoms, stuck to the anterior portion of the (flipped over) A-4 RV. 


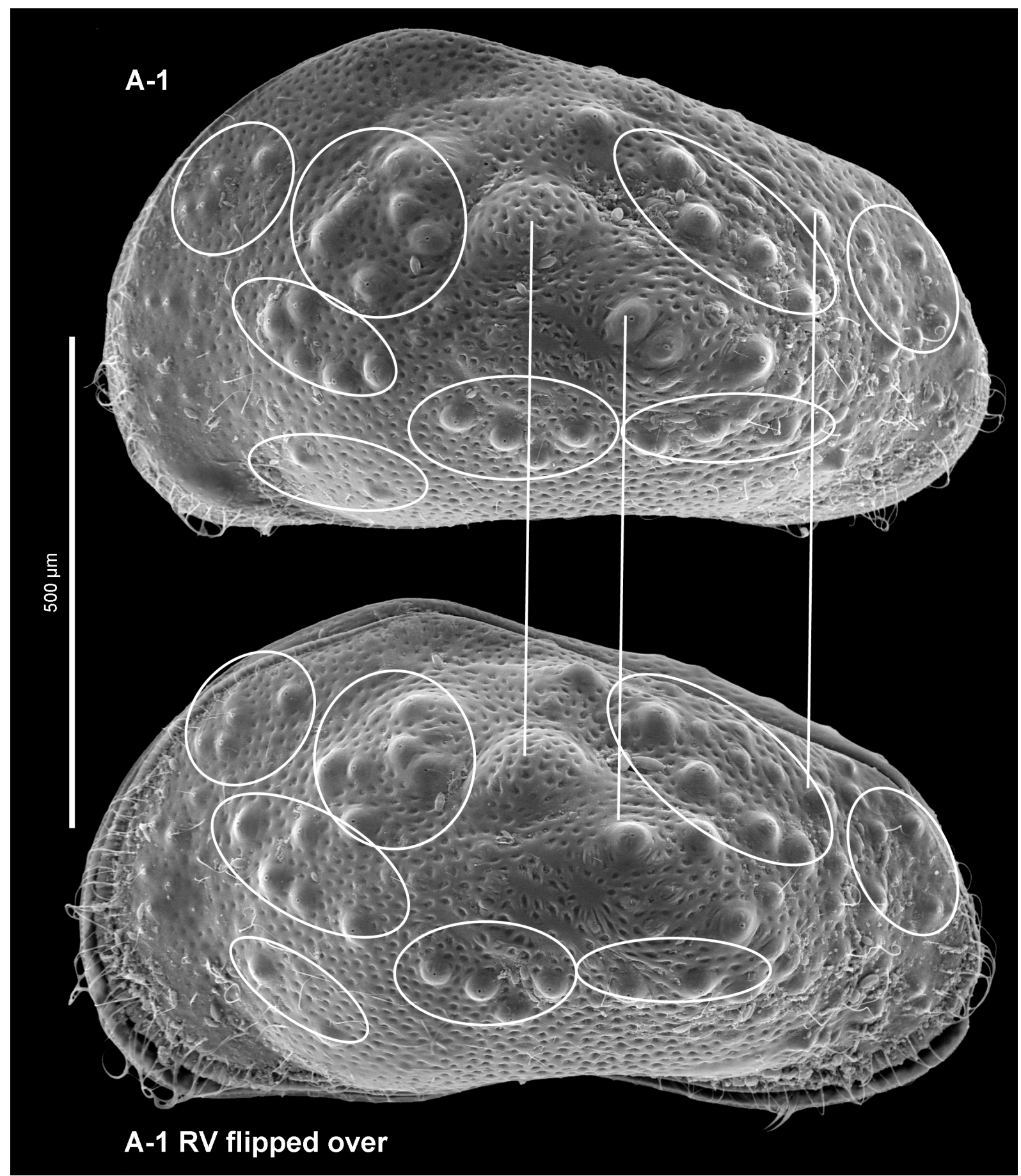

Fig. 10. External views of A-1 carapaces of Bennelongia cf. nimala nov. sp. juveniles from Muggon Lake. The top image shows an A-1 LV, whereas the bottom image shows a RV of an A-1 specimen that has been 'flipped over' digitally so as to permit comparison of the type of external ornamentation and respective location. Same comments as for Figure 9 concerning the white lines. 


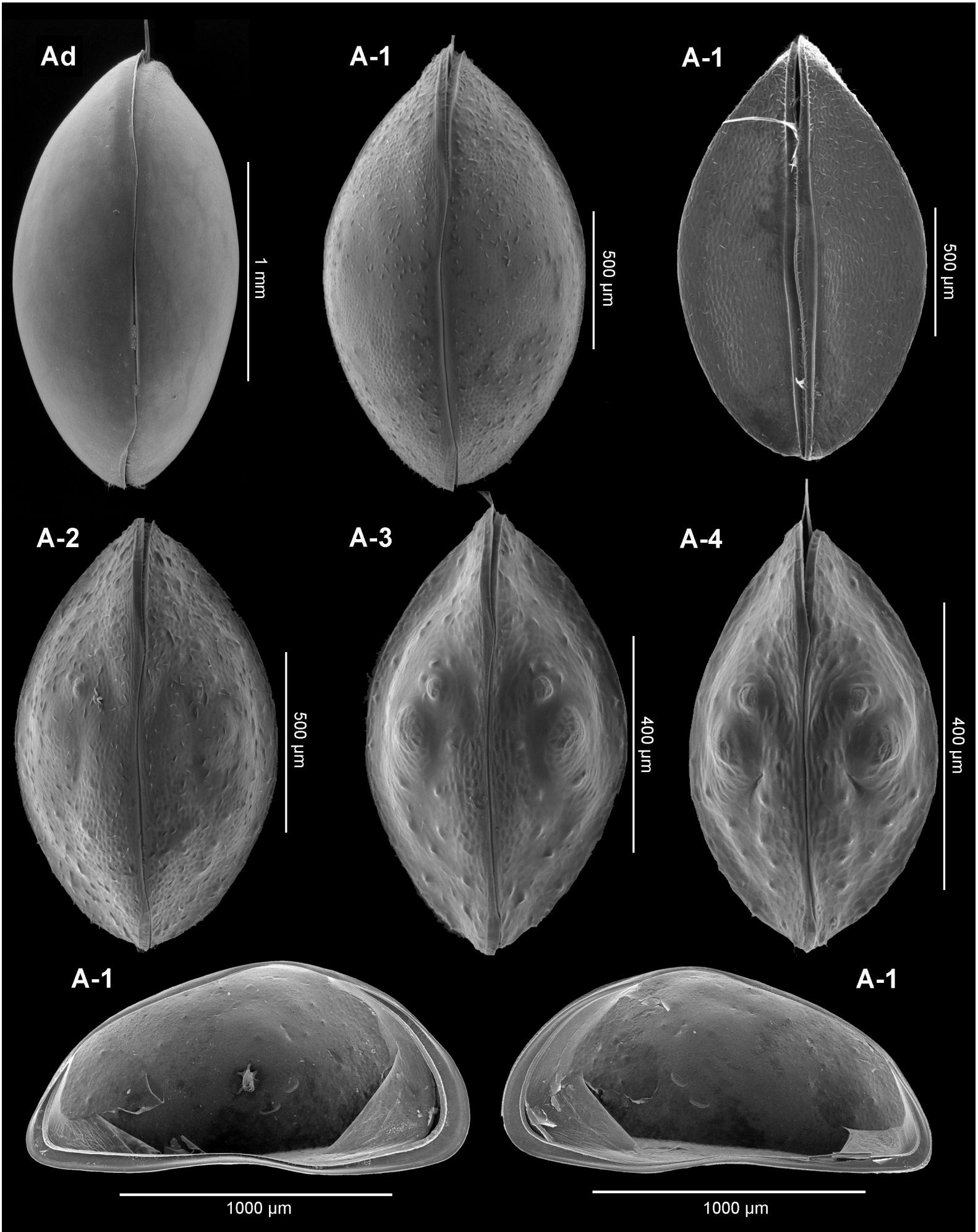

Fig. 11. Bennelongia sp. 414 nov. sp. from locality CB35a at Wooramel Station (Halse et al. 2000). For the top two rows, all views are dorsal, except top right image which is a ventral view. The bottom row consists of internal views of the two valves of an A-1 specimen. Note that the domes are only visible in A-2, A-3 and A-4 specimens, with possibly a second set of smaller ones positioned anterior to the larger one. The cones, which are few in number, are also very small and only clearly visible in A-3 and A-4 specimens. 

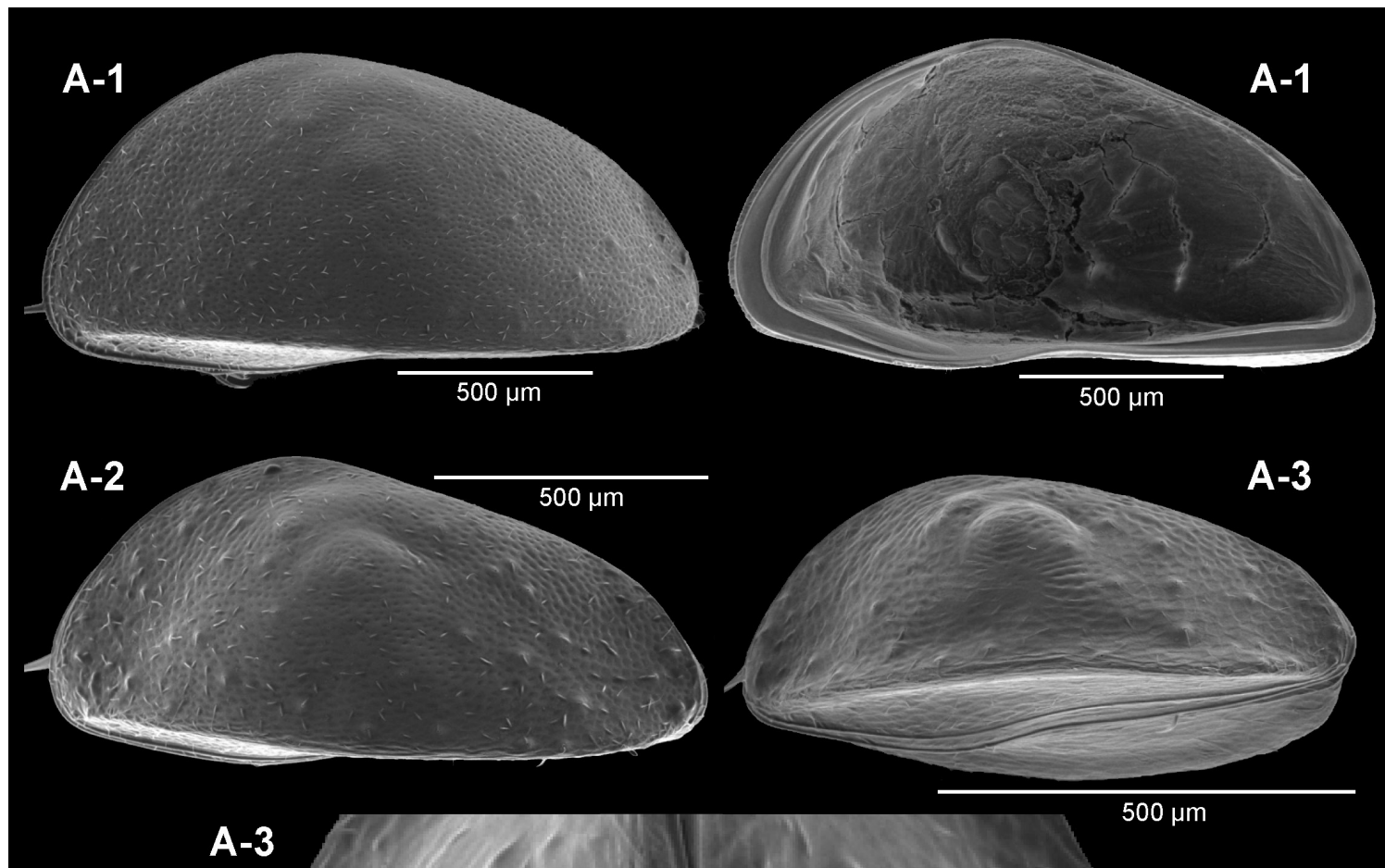

$500 \mu \mathrm{m}$

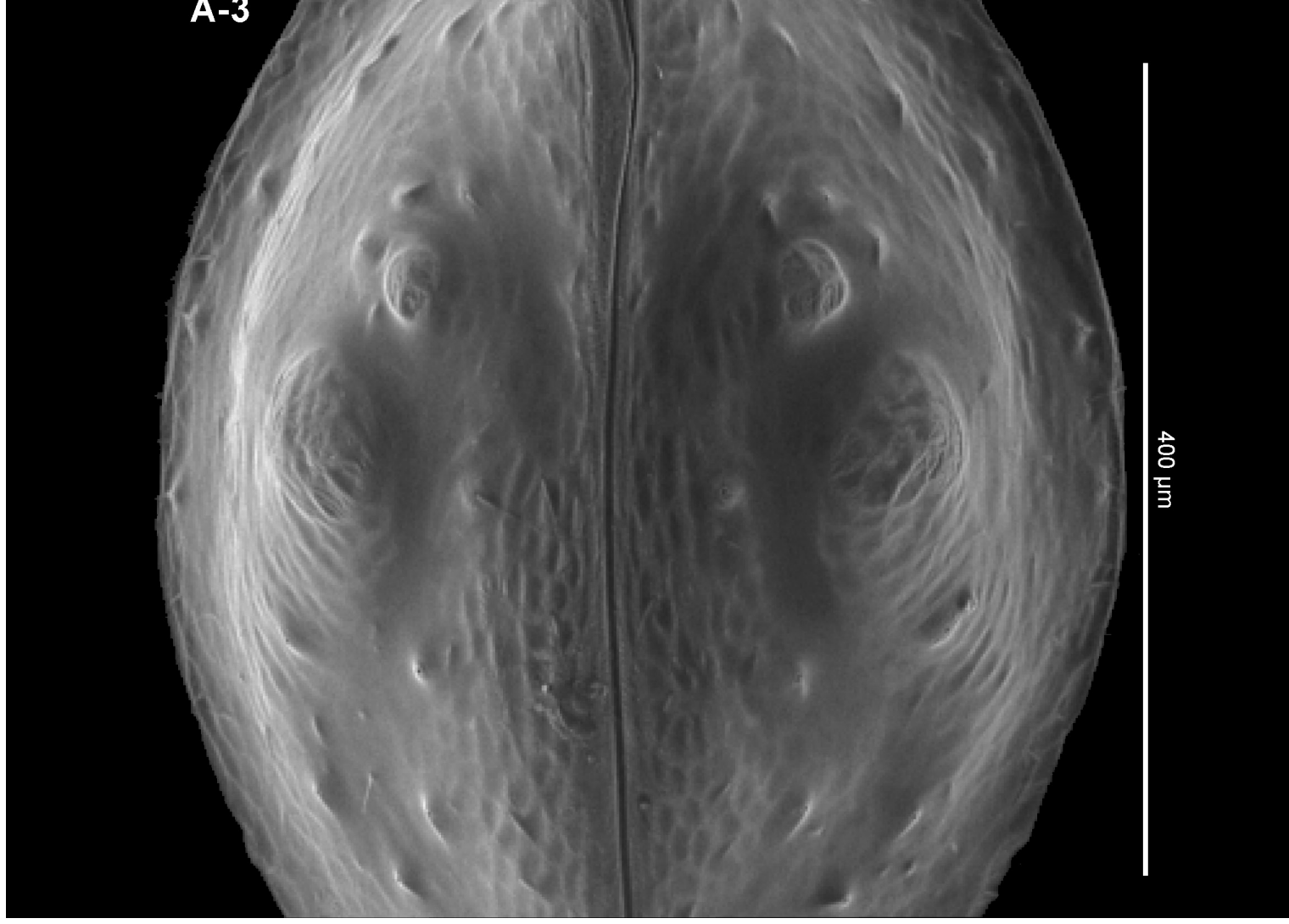

Fig. 12. Bennelongia sp. 414 nov. sp. from locality CB35a at Wooramel Station (Halse et al. 2000). All views are external, except for the right valve displayed at the top right hand corner. As for Figure 11, note that the domes and cones are much more discrete. This is particularly obvious in the bottom image that displays a dorsal view of the carapace of an A-3 juvenile. Note also that the internal view does not show a depression at the location of the dome. The middle right image shows the obvious lateral ridge that defines this new species. 


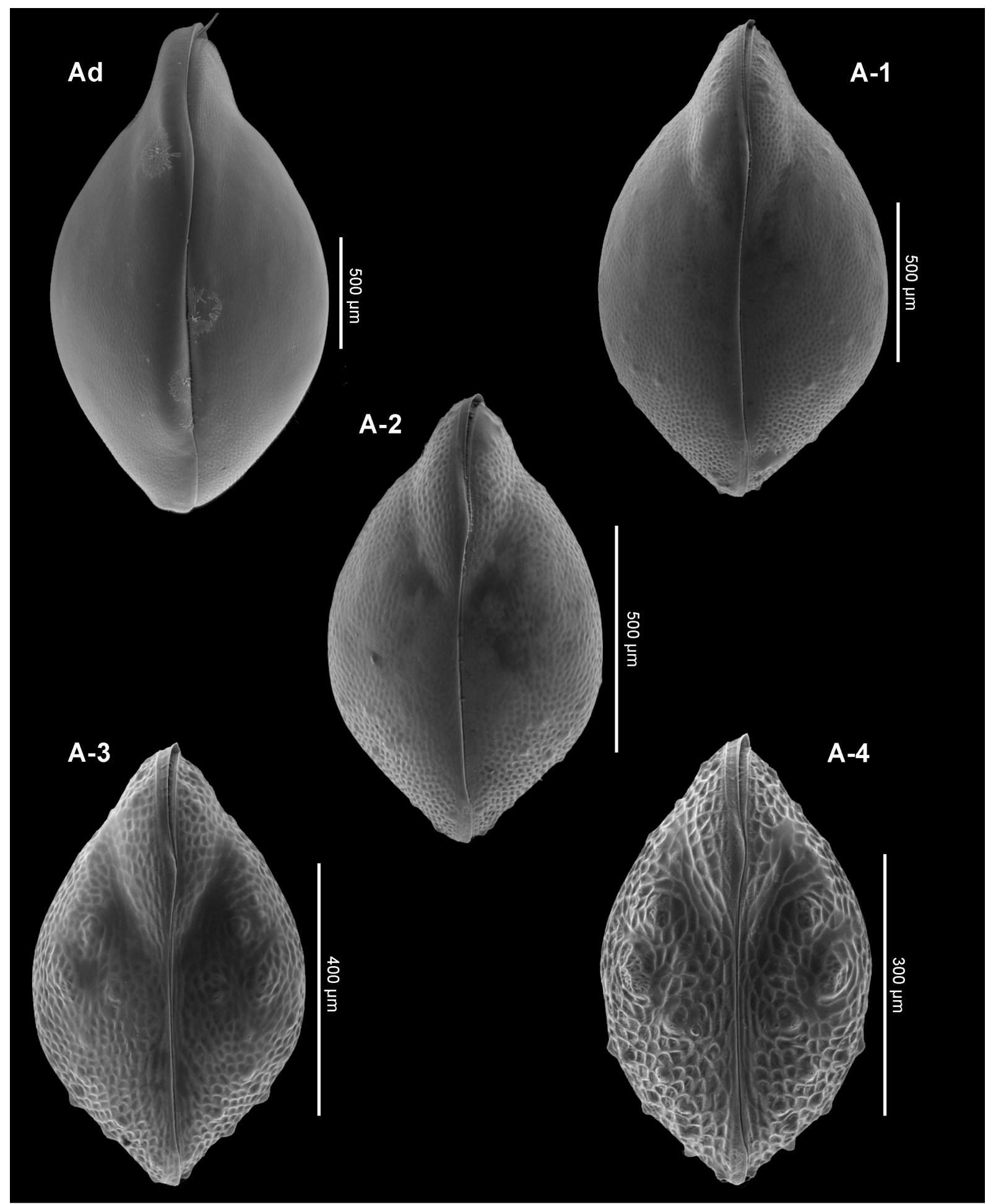

Fig. 13. Bennelongia kimberleyensis Martens et al., 2012 from Taylor's Lagoon. Dorsal views of carapaces of different moult stages going from adult to A-4. Note the highly ornamented A-4 carapace with at least 2 sets of domes (and prominent cones) that are still visible in A-3, and not visible in the other stages. Only a few cones are seen in the A-1 specimen, and no ornamentation is visible in the adult specimen. 


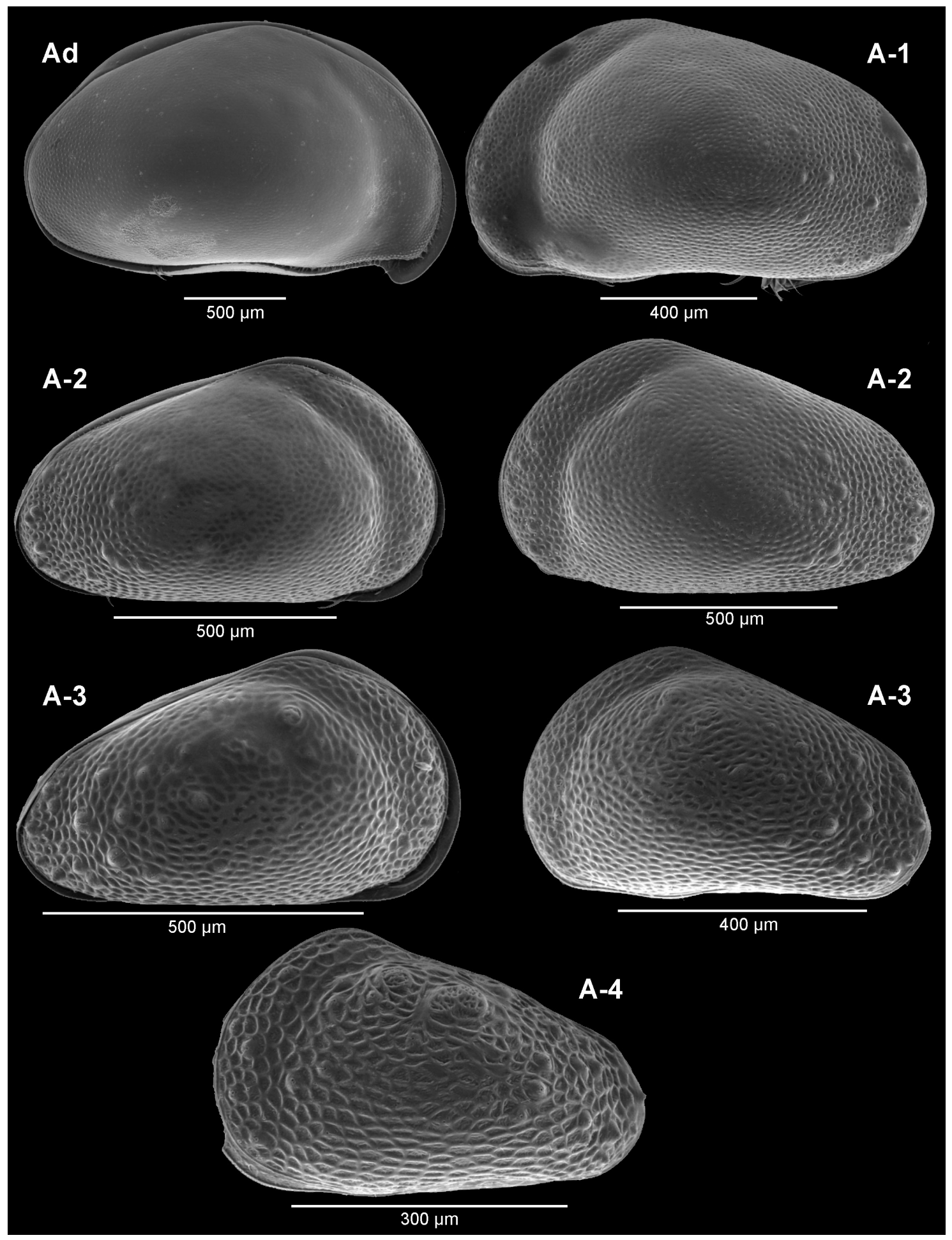

Fig. 14. Bennelongia kimberleyensis Martens et al., 2012 from Taylor's Lagoon. Lateral views of carapaces of different moult stages going from adult to A-3 specimens, plus a lateral view of a single LV of an A-4 specimen (bottom image) that is partly broken along its anterior margin. Top left image represents an adult showing the asymmetric valves, with the antero-ventral beak-like expansion of the LV that is the characteristic of most Bennelongia species in the adult stage. Right lateral views are in the left column, left lateral views are in right column. Note that the pseudo-punctation is more pronounced in the youngest stages compared to the almost smooth nature of the adult valve. 


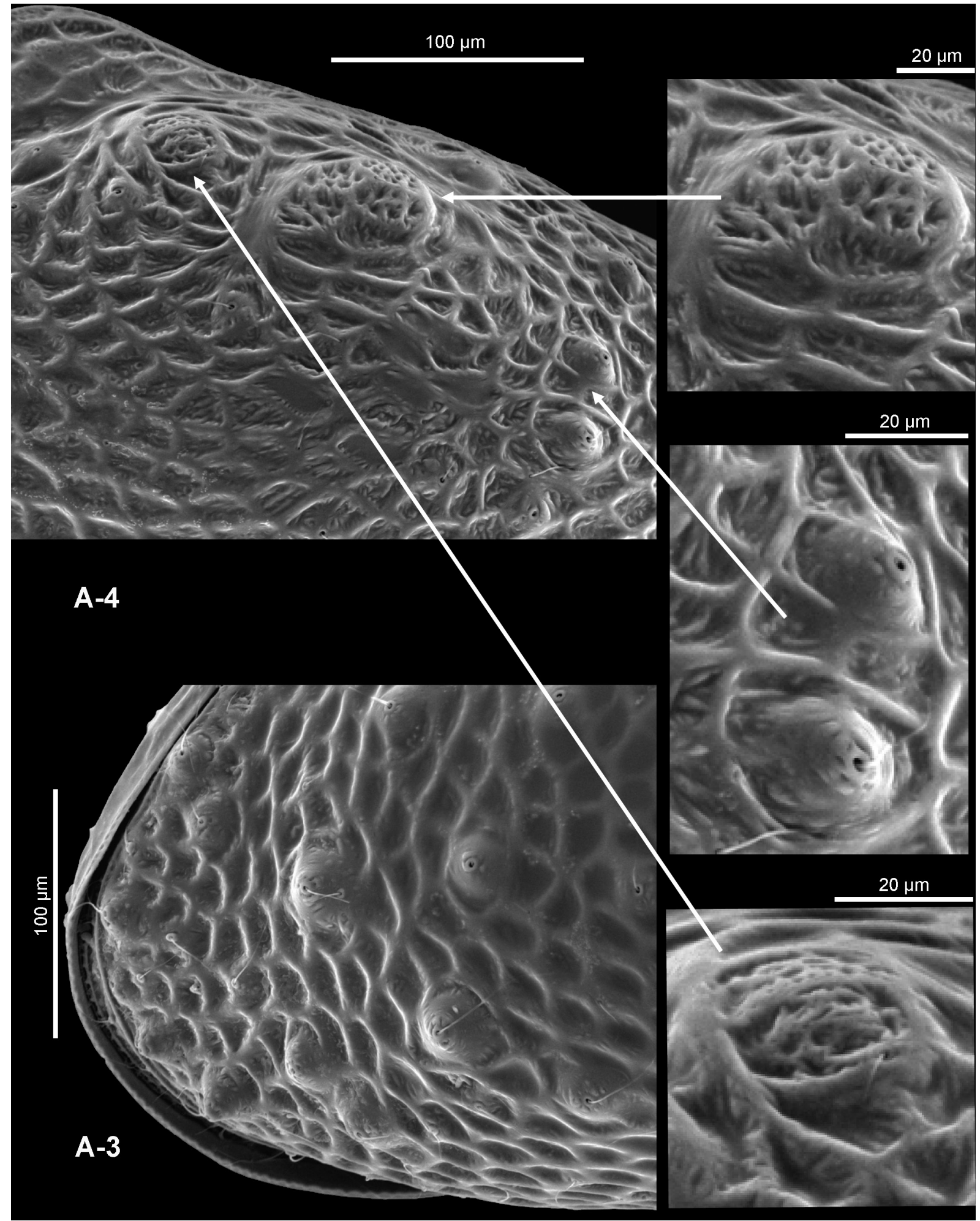

Fig. 15. Detailed views of the domes and cones of A-3 and A-4 specimens of Bennelongia kimberleyensis Martens et al., 2012 from Taylor's Lagoon. Note the micro-reticulated nature of the domes seen in the top left image in comparison with the rest of the valve the domes are enlarged in the top and bottom images on the right. The bottom left image and middle image on the right clearly show the cones with a lip near the apex and the protruding seta adorning each cone. 


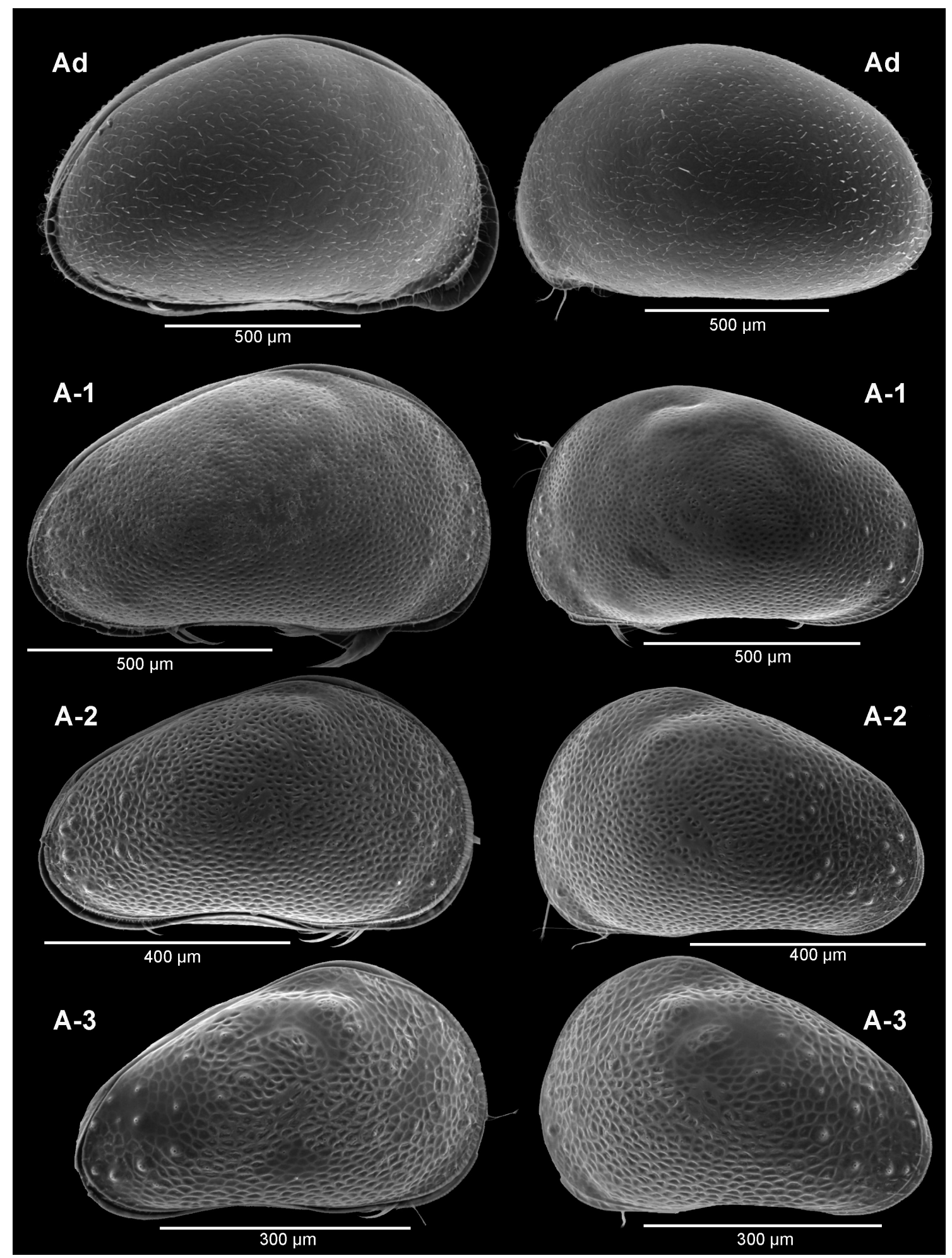

Fig. 16. Lateral views of carapaces of Bennelongia cf. barangaroo nov. sp. from McNeil Claypan. Left column displays carapace in right lateral view, right column shows carapaces in left lateral view. Note the pronounced asymmetry between the adult valves and the less-pronounced beak-like feature of the anteroventral region of the adult LV. Pseudo-punctation is more pronounced in the younger instars and the domes and cones are only clearly visible in A-3 specimens, although remnants remain in the last two juvenile stages. 


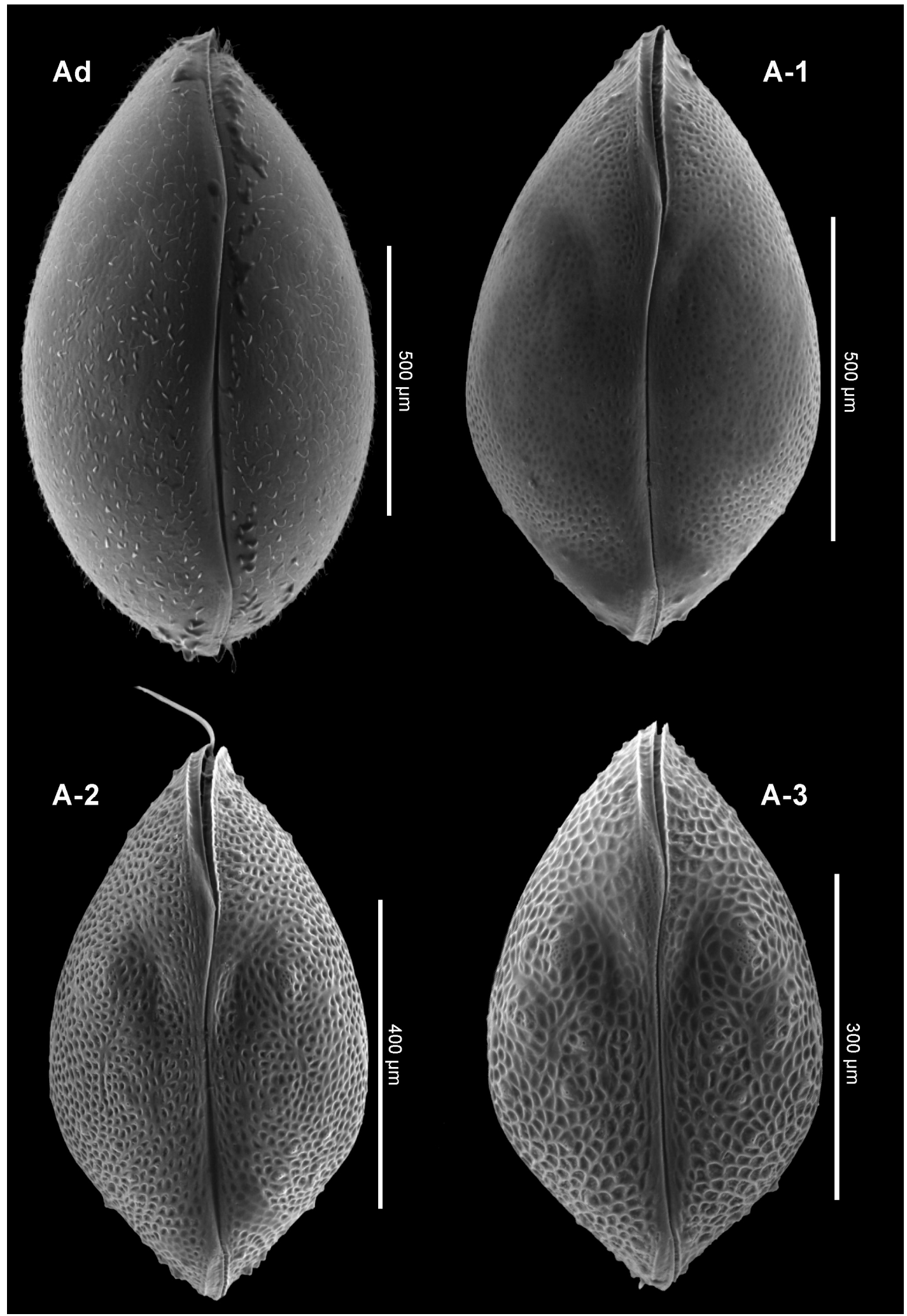

Fig. 17. Dorsal views of carapaces of Bennelongia cf. barangaroo nov. sp. from McNeil Claypan. Observe the coarse reticulation in A-3 specimens and the pseudo-punctuation that becomes less visible with progressing ontogeny. The adult specimen in top left image displays some agglomeration of glue along the hinge, particularly in the anterior and posterior regions. 


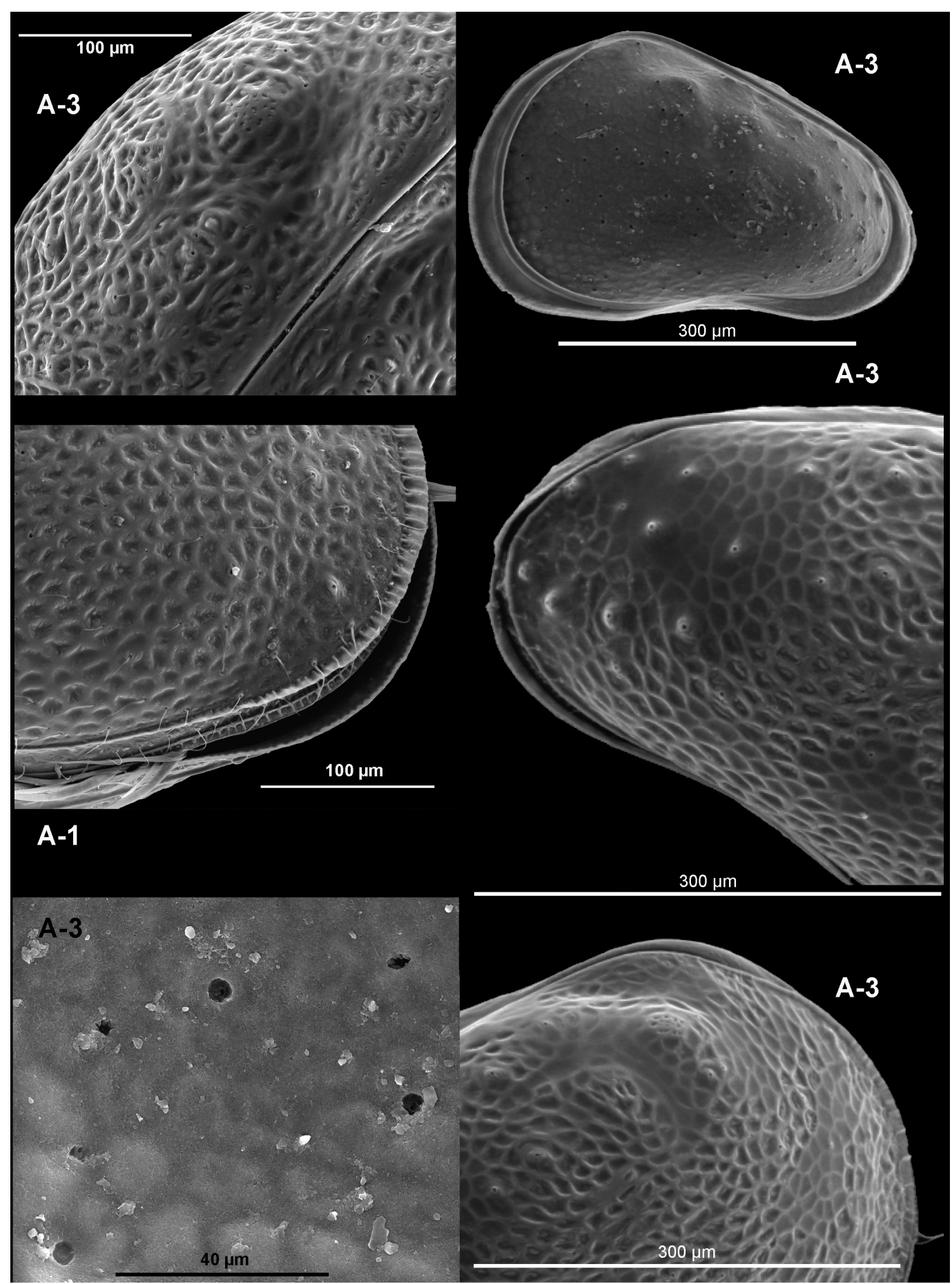

Fig. 18. Specimens of Bennelongia cf. barangaroo nov. sp. from McNeil Claypan, to show specific features of juvenile specimens. Top left image shows the poorly pronounced domes in the dorsal region of the LV of an A-3 specimen. Top right image shows an internal view of an A-3 that shows the less pronounced inner list and the depression located opposite the cones and the possible larger depression matching the external dome. The middle images show the cones with the lips near their apex. Bottom left image shows the larger pores on the inside of the valve, that are connected to the opening of each pore on the apex of each cone. Bottom right corner image shows the highly reticulated texture of an A-3 valve and the domes that are not as pronounced as in other Bennelongia species (e.g., compare to B. nimala nov. sp. in Fig. 3). 


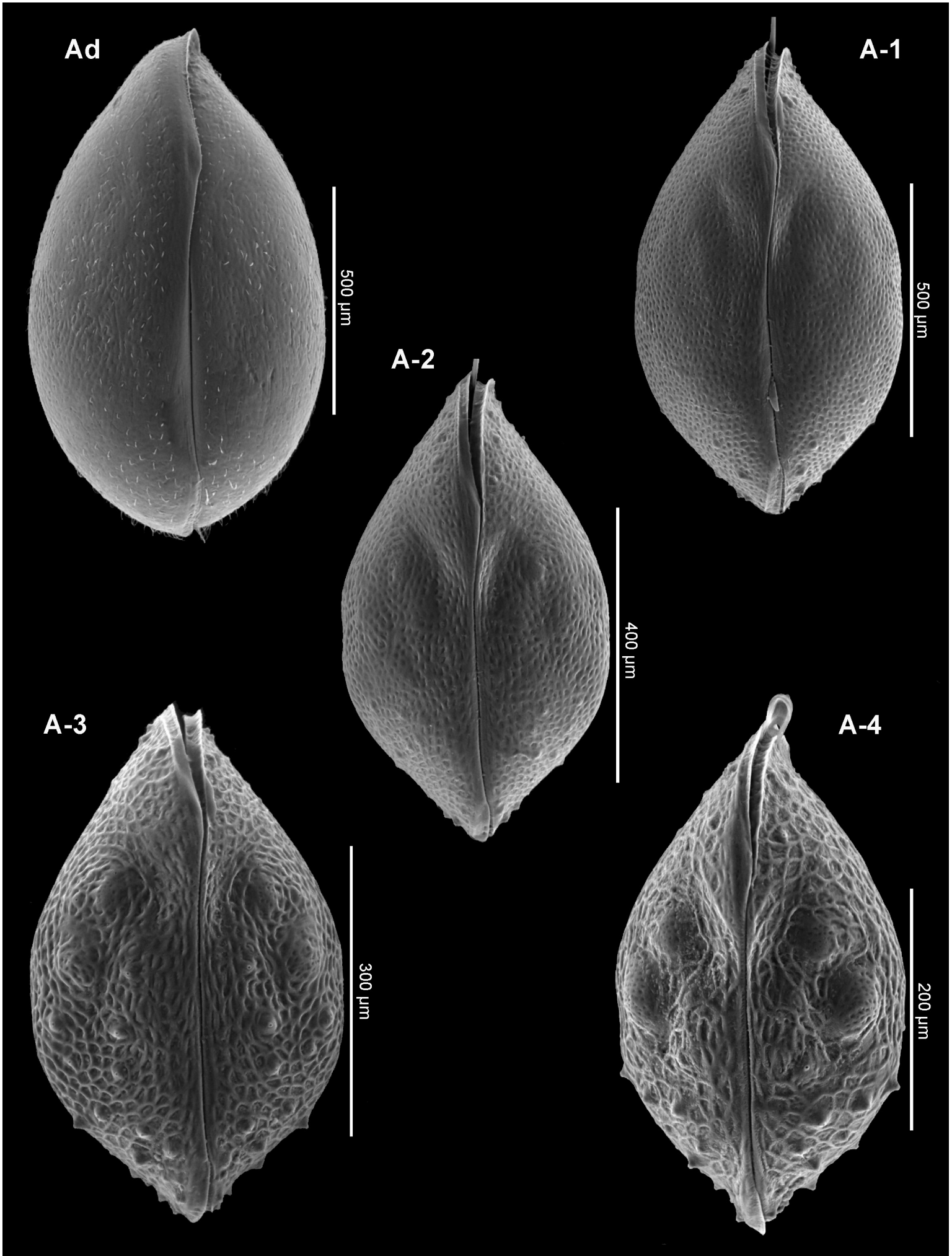

Fig. 19. Dorsal views of carapaces of Bennelongia dedeckkeri Shearn et al., 2012 from Lake Dunn (Queensland) for the last 4 instars (A-4 to A-1) and the adult to show the changes in external ornamentation and the progressive disappearance of the domes and cones with ontogeny, such that at the adult stage, there is no ornamentation. Observe the presence of outer lists in all juvenile specimens clearly visible in the antero-dorsal region. 

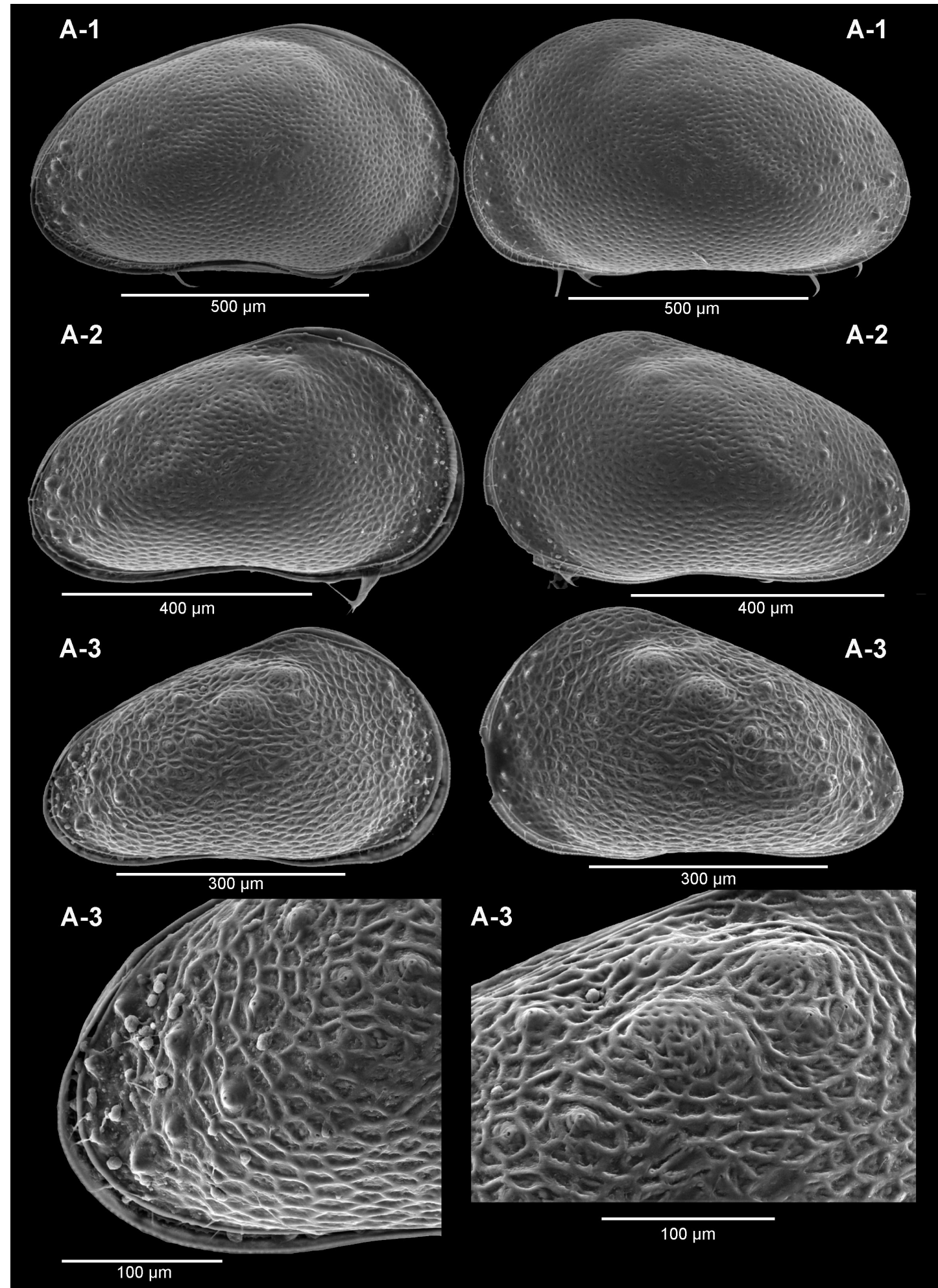

Fig. 20. Lateral views of carapaces of Bennelongia dedeckkeri Shearn et al., 2012 from Lake Dunn for the last 3 instars (A-3 to A-1) to show the changes in external ornamentation and the progressive disappearance of the domes and cones with ontogeny. Right lateral views are displayed in the top 3 left images, and left lateral views on the right. Details of the cones (bottom left) and the domes with fewer cones (bottom right) of A-3 specimens are portrayed. Note the presence of nodules stuck to the anterior portion of the valve of bottom left specimen. 

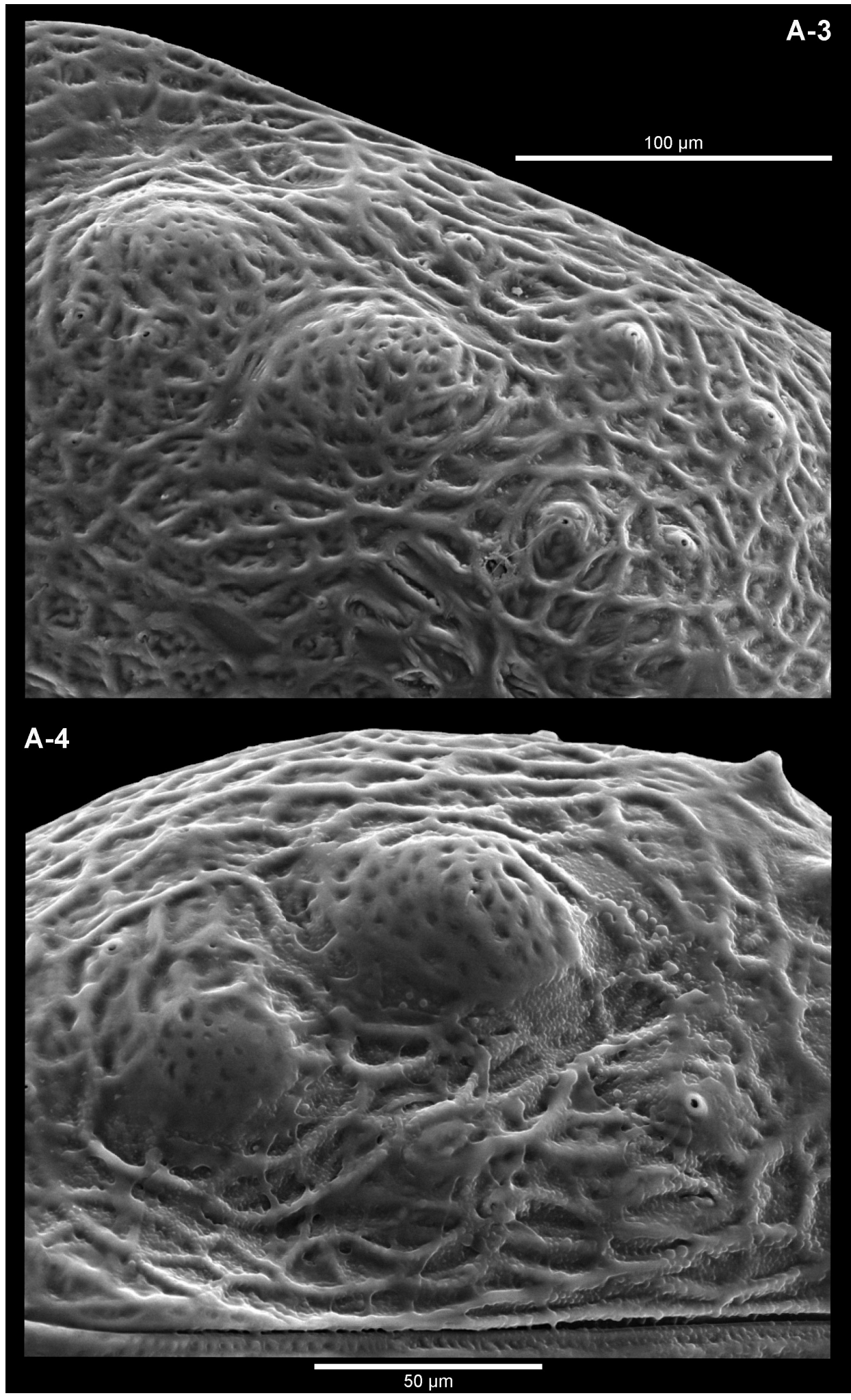

Fig. 21. Detailed views of carapaces of Bennelongia dedeckkeri Shearn et al., 2012 from Lake Dunn to show the domes in both images and 4 cones in the top image of an A-3 specimen, and only one cone in the image of an A-4 specimen. Note the interlacing reticulation around the domes, and the small nodes coating the valves, with 2 different diameters best seen to the right of the largest dome. These nodules are thought to be part of the valve ornamentation. 


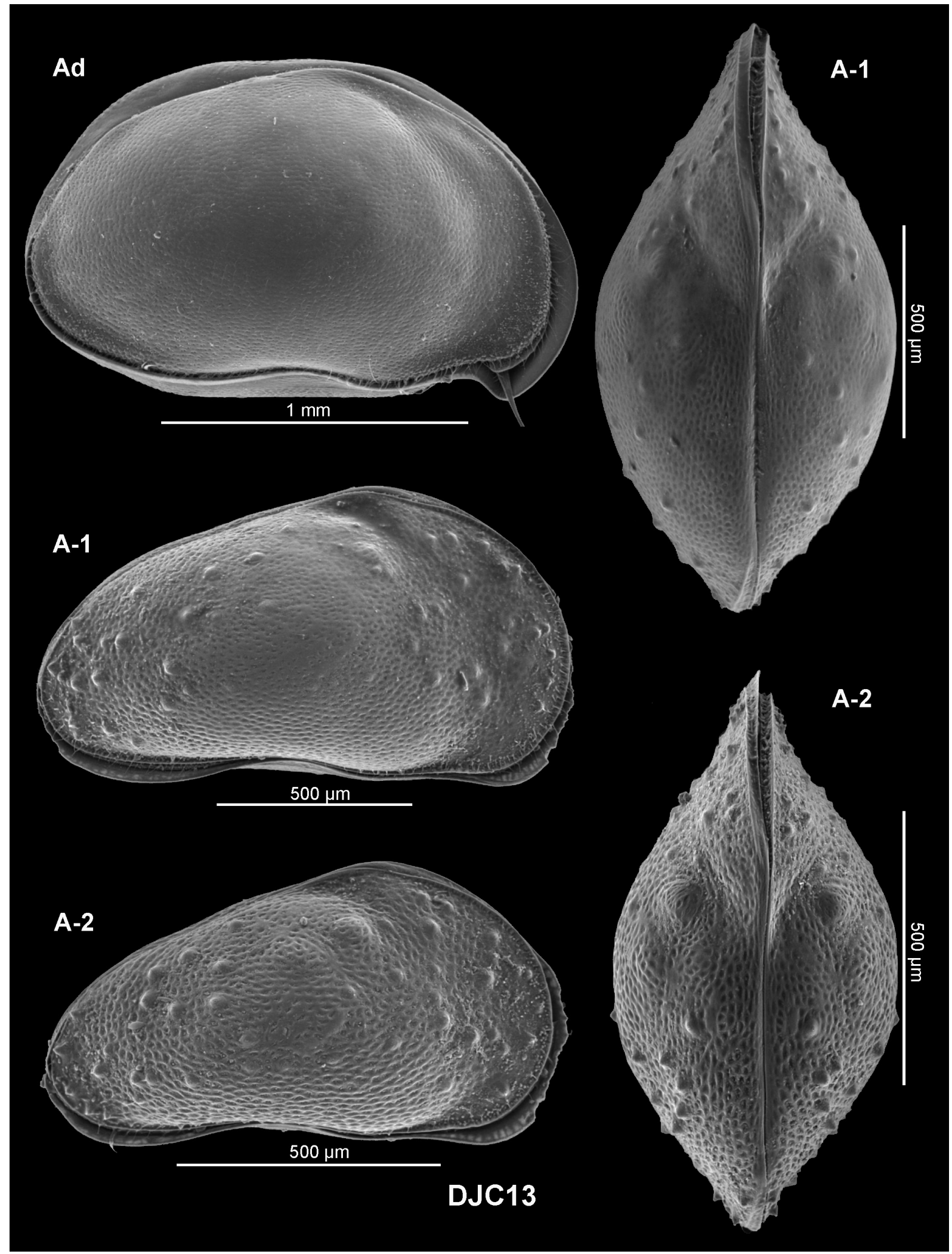

Fig. 22. External views of carapaces of Bennelongia gwelupensis Martens et al., 2012 from Arro Swamp. Right lateral views in left column for adult, A-1 and A-2 specimens, and dorsal views on the right of A-1 and A-2 specimens. Note that the ornamentation becomes progressively more intricate at younger stages. 


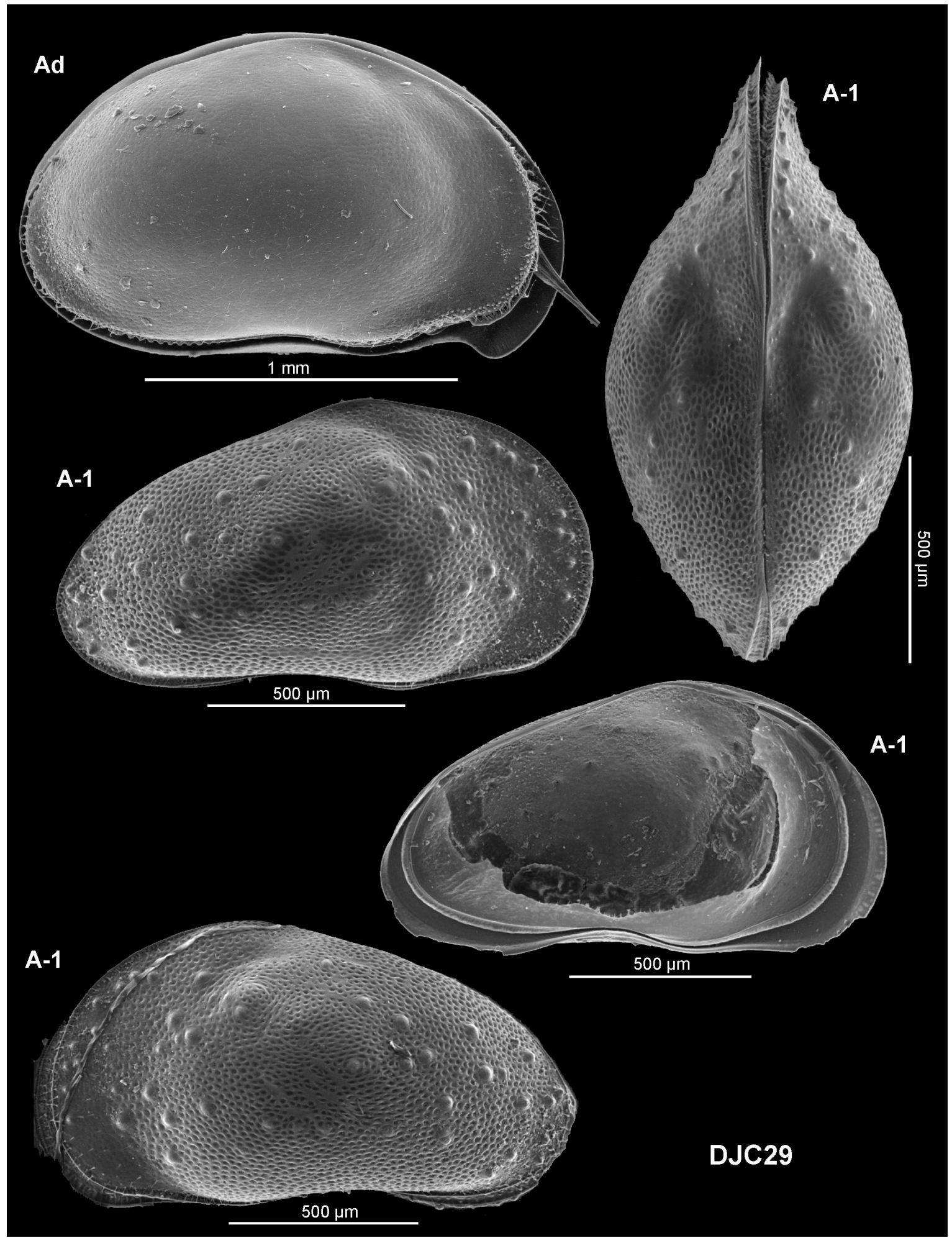

Fig. 23. External views of Bennelongia gwelupensis Martens et al., 2012 from Katanning Road pool, except for the middle image on the right which shows an internal view of a LV. Top left image represents the right lateral view of an adult carapace, with the antero-ventral beak-like expansion of the LV. In the internal view of the A-1 LV, note the depressions seen internally that mirror the cones that occur externally. A prominent inner list is visible all along the periphery of the valve, except in the dorsal region. This latter feature is usually not seen in juveniles ostracods. 

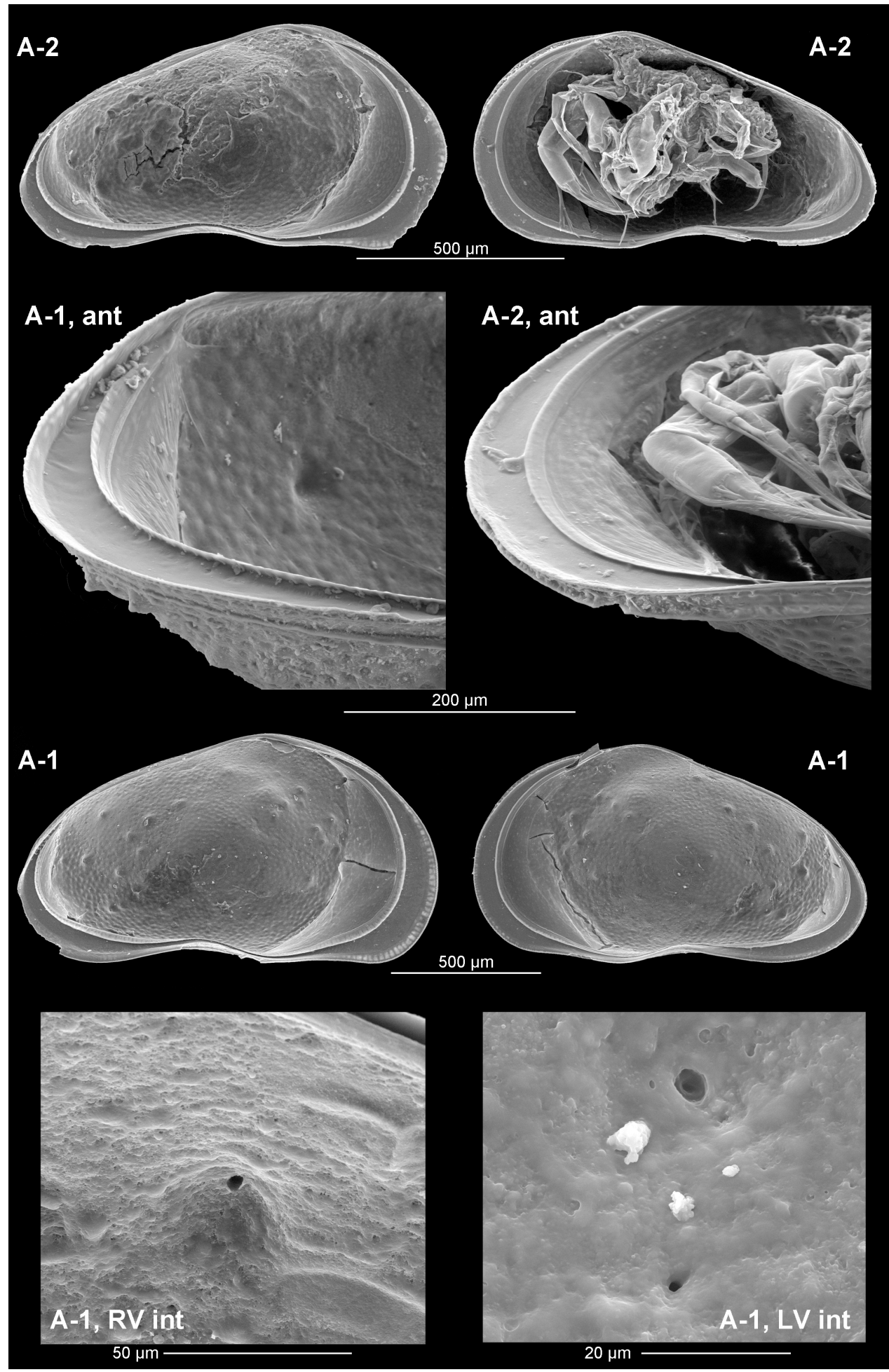

Fig. 24. Internal views of juvenile specimens of Bennelongia gwelupensis. Top row. internal views of A-2 juveniles from Arro Swamp (LV on left and RV on right with appendages). Second row. details of internal views of anterior RV (tilted) of A-1 specimen from Katanning Road pool on left, and A-2 on right which is the same specimen as the image above, but tilted. Third row. internal views of A-1 juveniles from Katanning Road pool (LV on left and RV on right); same specimen as detail left above. Bottom row.detail of internal views of RV on left and of $L V$ on right; both are the same A-1 specimens as the images above, to show that the pores on the cones connect with the inside of the valve. 